مطالعه اثر اسيد جاسمونيك و اسيد هيوميك بر برخى شاخصهاى جوانهزنى بذر جاى ترش ترش تحت تنش شورى (Hibiscus sabdariffa)

حميده آزاد '، بهمن فاضلى نسب ‘."، على سبحانىزاده”

\author{
' دانشآموخته كارشناسى ارشد اصلاح كياهان باغبانى، دانشكده كشاورزى، دانشعاه زابل

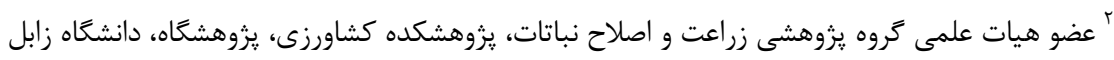

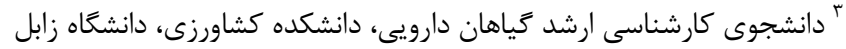

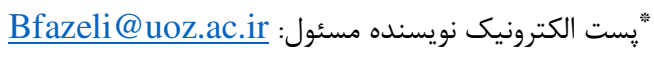

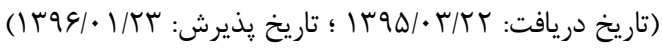

جكيده

اين يزوهش بهمنظور مطالعه اثر هورمونهاى رشد آلى اسيد جاسمونيك و اسيد هيوميك بر برخى

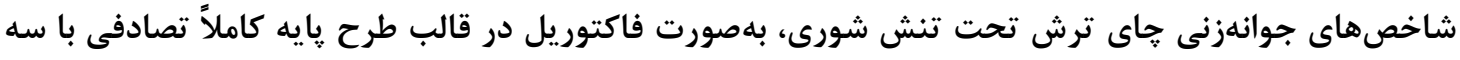

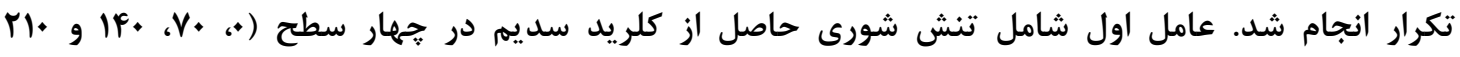

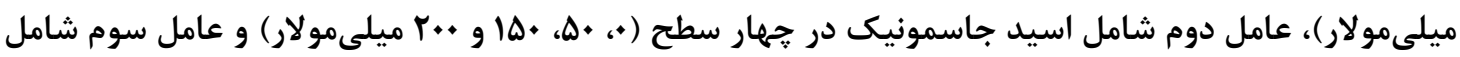

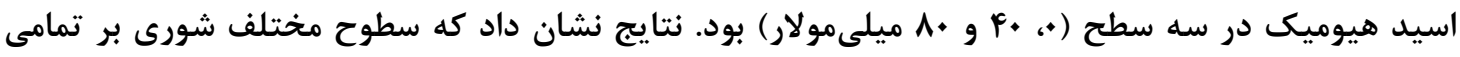

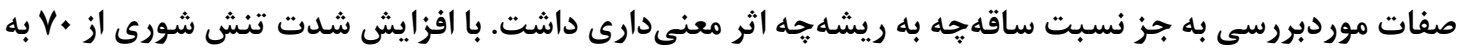

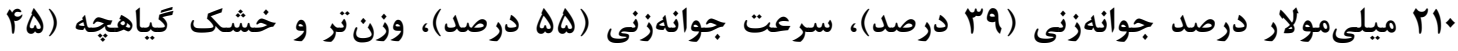

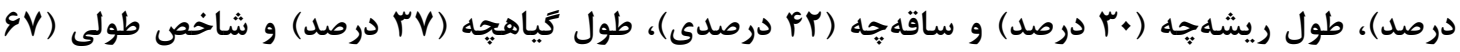

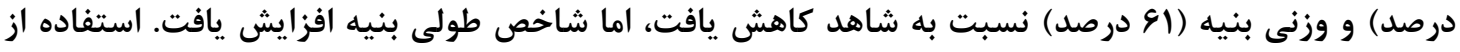

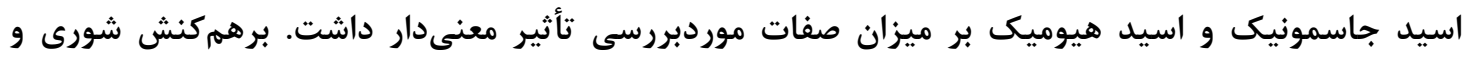

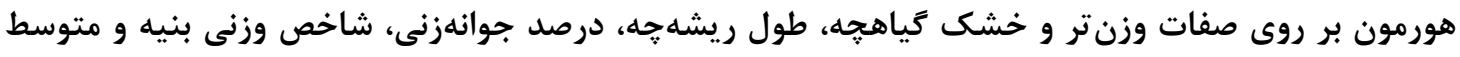

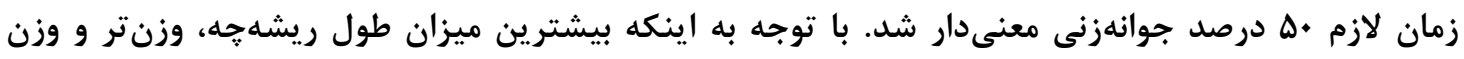

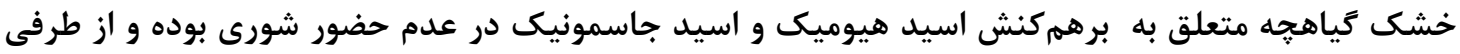

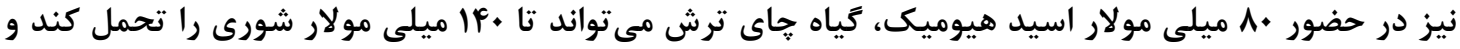
دجار كاهش طول ريشه جه نشود و با افزايش اسيد جاسمونيك (•r ميلى مولار) نيز جوانهزنى بيشتر شده، لذا

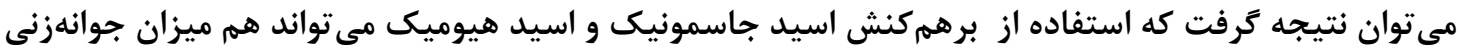

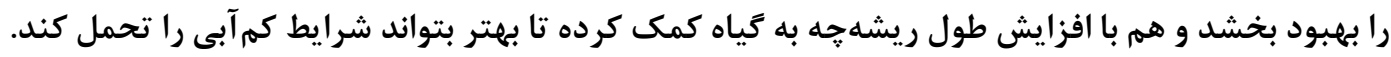

وازههاى كليدى: اسيد هيوميك، اسيد جاسمونيك، جاى ترش، شاخص بنيه بذر، كلريد سديم

جنبdهاى نوآورى:

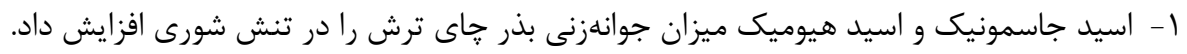

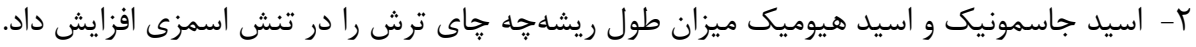


اشاره كرد (سايرام و وممكاران، هـ • (Y). مقاومت كياهان به تنشهاى محيطى در مراحل مختلف خرخه زندائى متفاوت است و معمولاً در اغلب كياهان، مرحله ابتدايى دريى رشد بلعنوان حساسترين مرحله رشدى تلقى مىشود

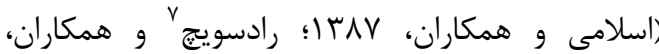

.(199V

شورى در خاك، يكى از تنشهاى مهم نواحى

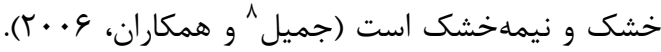
در ايران كه داراى اقليم خشك و نيمهخشك است، تنش شورى يكى از موانع توليد محسوب مى شود (مقصودى

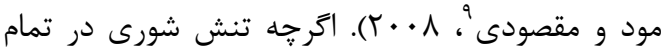
مراحل رشدى گياه مىتواند رخ دهد، اما با توجه به به اينكه استقرار اوليه كياه در عملكرد نهايى تأثير زيادى دارد تنش شورى در مرحله گياهجهاى براى زئن

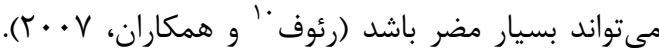
شورى در ابتدا باعث كاهش جذب آب توسط بذرها به دليل يتانسيل اسمزى منفى محيط شده و در مرحله

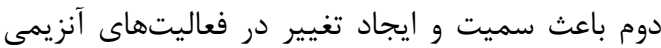
مىشود. سرعت زياد تجمع نمك در سلولهاى در حال نمو از دلايل حساسيت كياه به شورى در در اين مرحله هست (فرخى و كالشى، (צאז1) كزارش كردند كه شورى سبب كاهش درصد جوانهزنى كنكر وحشى شد و كاهش يتانسيل اسمزى عامل محدودكننده جوانهزنى بود؛ اما در غلظتهاى بـائ بالا

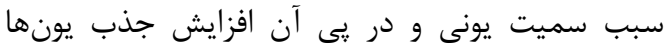
بهخصوص يونهاى نمك NaCl $\mathrm{NaCl}$ و عدم تعادل بين عناصر غذايى از عوامل مههم ايجاد اختلال و كاهش نامن درصد جوانهزنى محسوب مىشود (مقتولى و جايجى، إنى

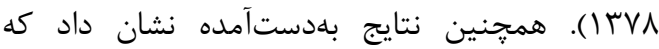

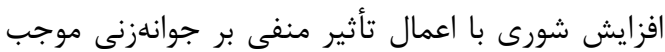

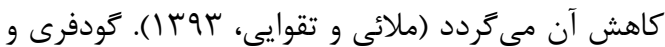

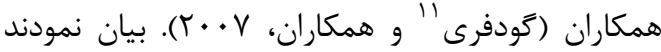
كه رسوب نمك در ريشه در حال رشد دليل اصلى

\footnotetext{
${ }^{6}$ Sairam

${ }^{7}$ Radosevich

${ }^{8}$ Jamil

${ }^{9}$ Maghsoudi Moud and Maghsoudi

${ }^{10}$ Rauf

${ }^{11}$ Godfery
}

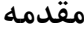

جاى ترش (Hibiscus sabdariffa) از خانواده ينيركيان (Malvaceae)، كياهى يكساله، شاخهدار، با

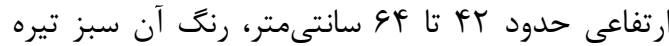

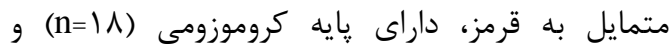

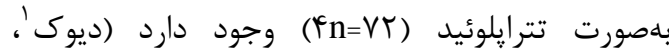
ra19). در ايران اين گياه و محصول كاسبرى آن

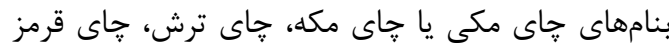
و קإى ترش شناخته مىشود. جاى ترش از ساليان قبل بلعنوان دارو استفاده مىشده و هماكنون نيز بهعنوان كياه دارويى موردتوجه

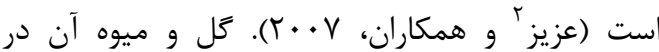
صنعت داروسازى براى تسكين علائم برونشيت و سرفه استفاده مىشود. براى درمان فشارخون بالا، اسهال و ورائ بيمارى دهان و ضد اسكوربيت (كمبود ويتامين ث) از إن كاسبركَهاى آن استفاده مىشود. همجنين در درمان سوءهاضمه و بيمارى كبدى و قلبى كاربرد دارد (فرجى انى

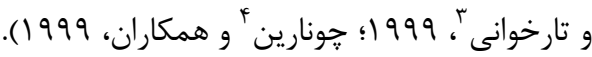
جوانهزنى بذر، يك فرآيند زيستى است كه در آن انواع مختلفى از عوامل زنتيكى و محيطى تحت تأثير

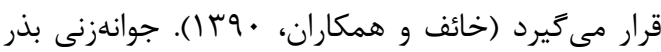
با جذب رطوبت در بافتهاى جنين آغاز مى كردد. در مراحل اوليه، انرزى از طريق فرايند كليكوليز فراهمشده و متابوليتهاى لازم براى سنتز مواد جديد را از طريق كريز راه ينتوز فسفات تأمين مى كند. هورمون جيبرلين با ارسال ييام لازم براى سنتز آنزيمهاى هيدروليز كننده، موجب تجزيه مواد ذخيرهاى در آندوسيرم دانه مى بشوند.

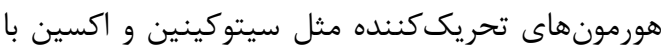
تحريك تقسيم و طويل شدن سلول باعث رشد، افزايش تنفس در ميتوكندرى، سنتز يروتئينها، رشد و ظهور

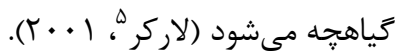
تنشهاى محيطى زيادى بر رشد و نمو و توليد

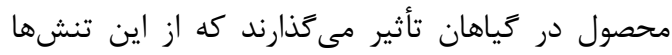
مىتوان به خشكى، سرما، گرما، عناصر سمى و شورى

\footnotetext{
${ }^{1}$ Duke

${ }^{2}$ Aziz

${ }^{3}$ Faraji and Tarkhani

${ }^{4}$ Chewonarin

${ }^{5}$ Larcher
} 
طريق اثرات هورمونى (سماوات و ملكوتى، IMAF) و با

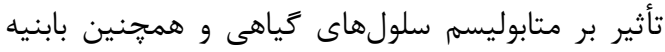
كلات كنندكى و افزايش جذب عناصر غذايى سبب افزايش رشد و ارتفاع كياه مى شود (ناردى بَّ و همكاران،

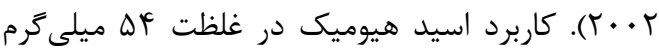
بر ليتر سبب افزايش معنىدارى در رشد ريشهجه و ساقهجه كندم از طريق افزايش جذب آب و مواد غذايى

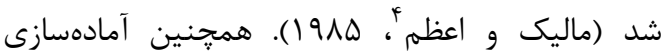
بذرهاى شمعدانى و هميشهبهار در محلول اسيد

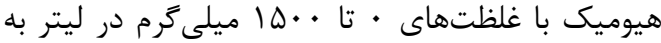

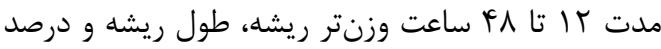

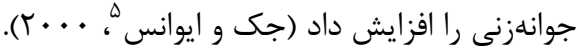
اسيد جاسمونيك و اسيد متيل جاسمونيك خانواده جديدى از هورمونهاى كياهى هستند كه در كل به آنها اسيدهاى جاسمونيك كفته مىشود و نقش مهمى

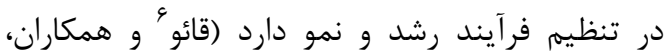

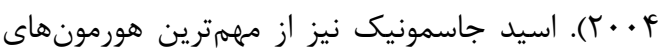
مقاومت به تنشهاى زيستى و غير زيستى است. اين هورمون بعد از زخم شدن كياه بهسرعت در بافتهاى

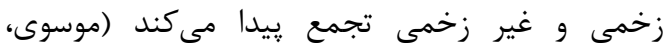
• وبا). استفاده از متيل جاسمونات و تركيبات مشابه راهكارى مؤثر براى افزايش توليد متابوليتهاى ثانويه كياه و مقاومت در برابر تنشهاى محيطى و وياتوزنها

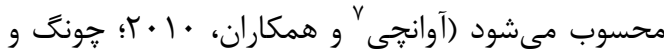

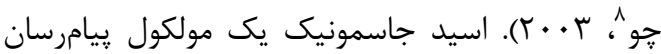

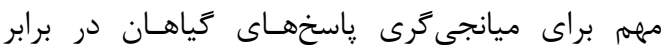

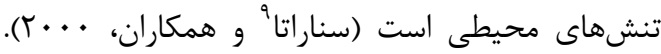

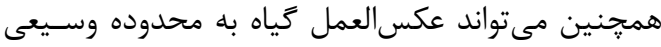

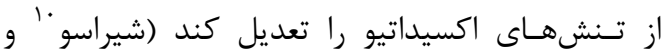

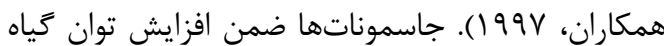
در برابر تنشهاى محيطى و زيستى، از طريق افزايش سطح برك و افزايش كربنگيرى، سبب افزايش وزن إنى

\footnotetext{
${ }^{3}$ Nardi

${ }^{4}$ Malik and Azam

${ }_{6}^{5}$ Jack and Evans

${ }^{6} \mathrm{Gao}$

${ }^{7}$ Avanci

${ }^{8}$ Cheong and Choi

${ }^{9}$ Senaratna

${ }^{10}$ Shirasu
}

خشكى فيزيولوزيكى و سيس كاهش تقسيم سلولى و درنهايت كاهش رشد ريشه و بنيه بذر است است نتايج محققان در مورد كياهان كوشيا (جامى الاحمدى و ورناف

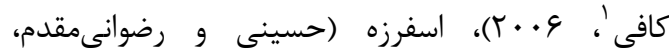

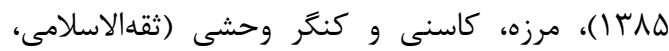

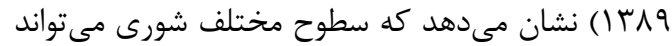
سرعت جوانهزنى را كاهش دهد.

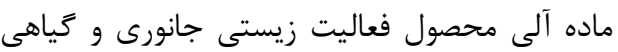
خاك است و شامل تمامى اجزاء اوليه آلى زنده و مرده، تازه يا تجزيه شده خاك است. باكترىها و قارتها مانداء الندا بقاياى كياهى و جانورى جزئى از بخش آلى خاكى

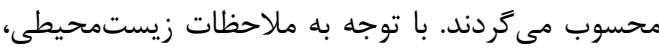

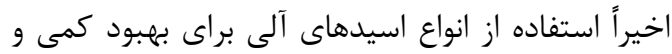

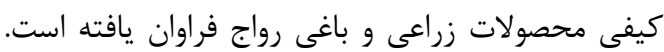
مقادير بسيار كم از اسيدهاى آلى اثرات فراوانى در بهبود

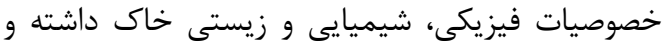
به دليل وجود تركيبات هورمونى اثرات مفيدى دري افزايش توليد و بهبود كيفيت محصولات كشاورزى دارد

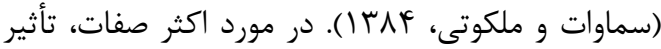
كودهاى آلى بلمراتب بيشتر از كودهاى شيميايى بوده كه احتمالاً به توليد بيشتر عناصر غذايى موجود در اين بين تيمارها در طول دوره رويشى و زايشى تياه مرتبط بوده

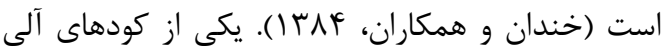

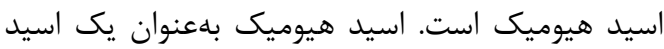
آلى حاصل از هوموس و ساير منابع طبيعى، بدون اثرات

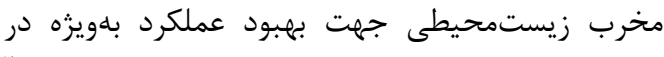

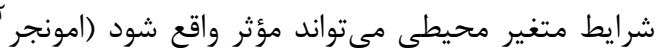
و همكاران، • 199). همجنين اسيد هيوميكى يكى دئ ديكر از كودهاى مناسب مورداستفاده در نظام كشاورزى آلى است. مهمترين خاصيت اسيد هيوميك اين است كه از از يك طرف به انحلال و آزادسازى عناصر تثبيتشده بخصوص در خاكهاى قليايى كمك مى كند و از طرف

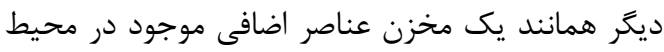
را در خود ذخيره نموده، بهموقع در اختيار ريشه

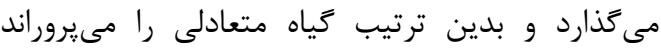

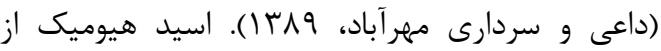

\footnotetext{
${ }^{1}$ Jami Al-Ahmadi and Kafi

${ }^{2}$ Emongor
} 
محسوب كرديد كه طول ريشهجه آن بهاندازه تقريباً دو

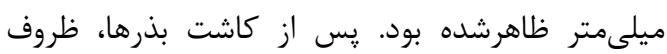

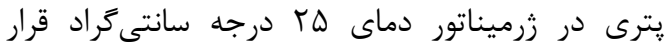

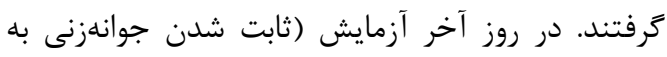

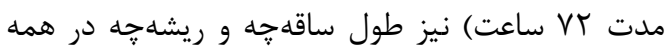
كياهجههاى جوانهزده اندازهخيرى شده و و بر اساس

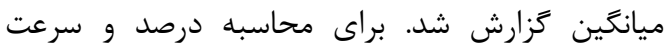

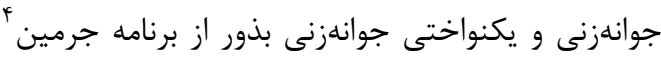

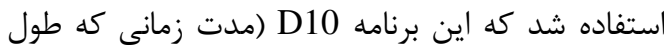

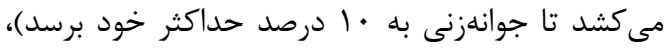

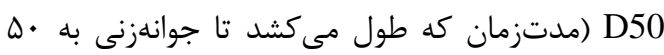
درصد حداكثر خود برسد) و D90 (مدتزمان كه طول

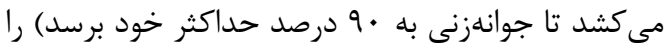
محاسبه مى كند. اين برنامه پارامترهاى يادشده را را براى

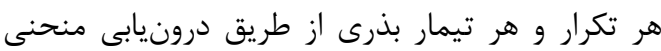
افزايش جوانهزنى در مقابل زمان محاسبه ميكى بند.

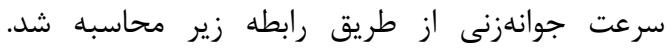

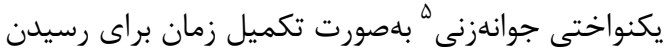

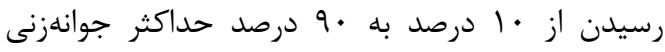

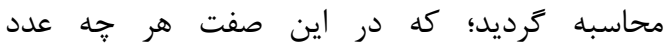
بهدستآمده كمتر باشد، نشان دهند يكنواختى بيشتر

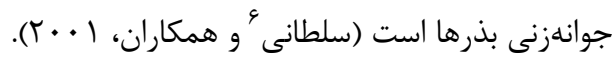
R50=1/D50

رابطه (1)

$\mathrm{GU}=\mathrm{D} 90-\mathrm{D} 10$

(r) رابطه (1) (1)

مدتزمان رسيدن به • ل، •ه و •9 درصد جوانهزنى

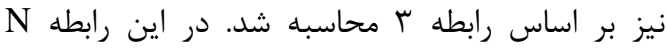

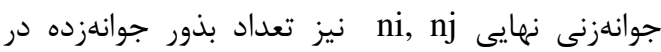

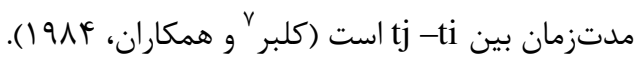

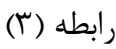

D10, 50, $90=\mathrm{ti}+[(\mathrm{N} / 2-\mathrm{ni})(\mathrm{tj}-\mathrm{ti})] /(\mathrm{nj}-\mathrm{ni})$

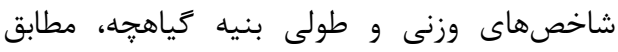

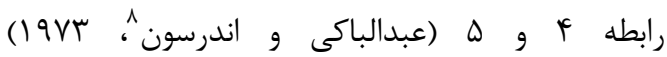
اندازميرى و محاسبه شد.

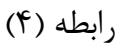

\footnotetext{
${ }^{4}$ Germin

${ }^{5}$ Germination uniformity (GU)

${ }^{6}$ Soltani

${ }^{7}$ Coolbear

${ }^{8}$ Abdul-Baki and Anderson
}

سوخ در يياز شدهاند (ماكسميس'، 11 (1) كار). كزارششده

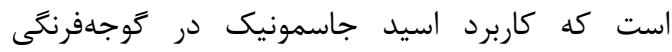
مىتواند با برطرف كردن تنش خشكى وضعيت كياه راسي

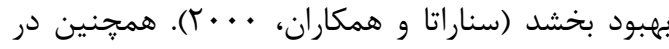
تحقيقى افزايش رشد ليهها با كاربرد متيل جاسمونات در كدو كزارششده است (استونوا بكالوا؟ و همكاران،

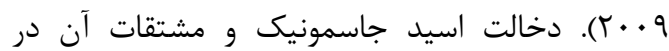

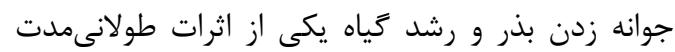
جاسموناتها است. تحقيق حاضر با هدف بررسى و مطالعه اثر تنش

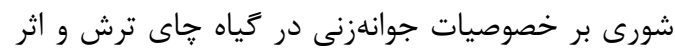
هورمونهاى رشد آلى (جاسمونيك و اسيد هيوميك) بر روى آن صورت كرفت.

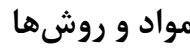

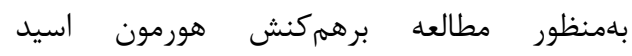

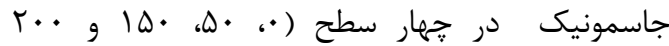

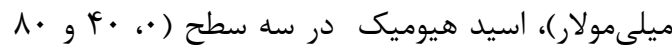

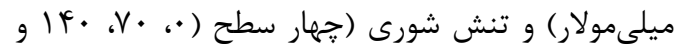

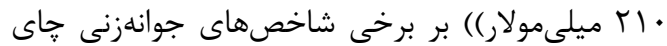

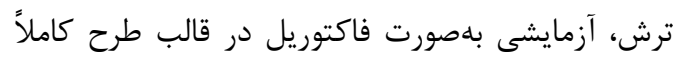

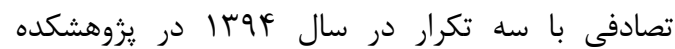

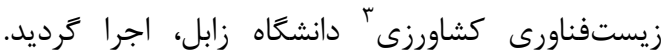

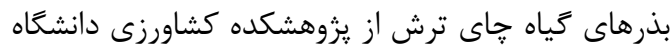

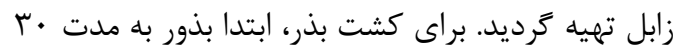

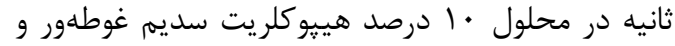
يس از ץ بار شستشو با آب مقطر، براى كشت آماده كرديد. بعد از جدا كردن بذرهاى سالم و هماندازه، تعداد

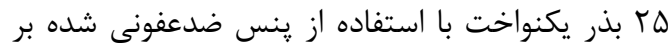
روى كاغذ جوانهزنى با فاصله مشخص قرار داده شدند و

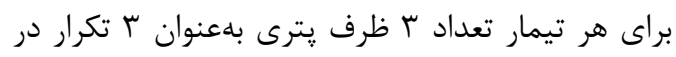

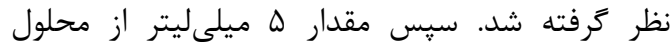

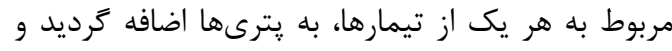

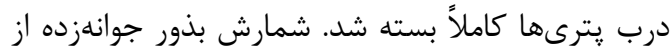
روز دوم كشت شروع شد. در اين تحقيق بذرى جوانهزده

\footnotetext{
${ }^{1}$ Maksymiec

${ }^{2}$ Stoynova-Bakalova

${ }^{3}$ http://cab.uoz.ac.ir
} 


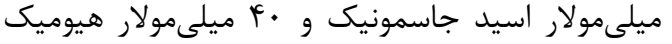

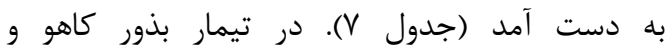
كوجهفرنكى در يترى ديشهاى حاوى اسيد هيوميك اهد

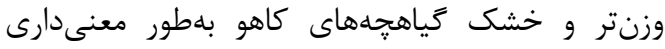

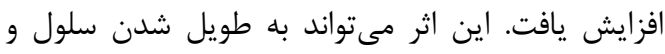
كارايى بيشتر در جذب آب مربوط باشد؛ درحالى كه

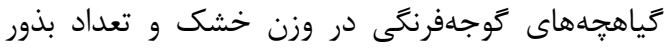

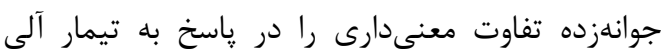

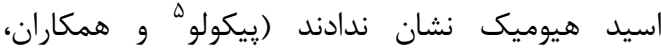

$(Y \cdot \Delta$

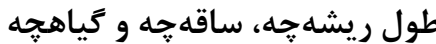
طول ريشهجه تحت تأثير اثرات اصلى شورى، جاسمونيك اسيد، هيوميك و برهم كنشها (بهجز اسيد الهيدي

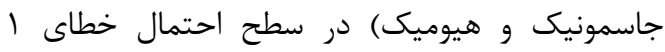
درصد قرار گرفت طول ساقهاه نيز تحت تأثير اثر شورى، اسيد هيوميك و برهمكنش شورى و واسيد جاسمونيك و اسيد جاسمونيك و هيوميك در سطح احتمال خطاى | درصد قرار گرفت (جدول ()). همجنين

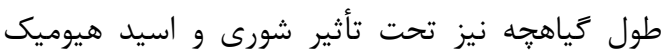

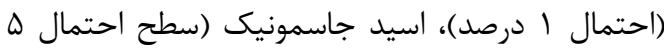

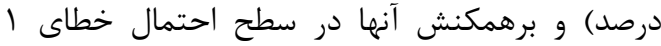
درصد قرار كرفت (جدول (). با توجه مقايسه ميانكين، اثرات شورى در اسيد جاسمونيك براى بيشترين مقدار

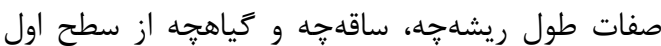

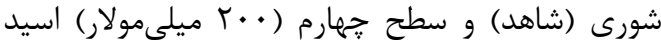

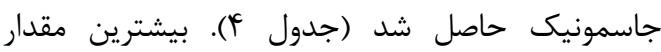
صفات ساقهجه و كياهجه از سطح اول شورى (شاهد) و

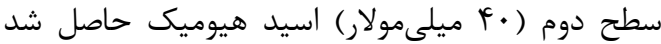

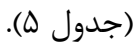

شاخص وزنى بنيه = وزن خشك گياهجه × درصد

$$
\text { جوانهزنى }
$$

(ابطه (ه)

شاخص طولى بنيه = طول گَياهجه × درصد جوانهزنى بعد از سيرى شدن طول دوره آزمايش و در روز

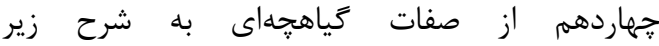

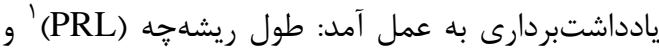

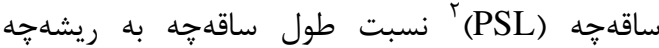
(PSL/PRL)، وزنتر كياهجه (SFW)

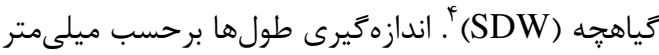
ميلىمتر و اندازهخيرى وزنها برحسب گرم و بلهوسيله ترازوى حساس ديجيتالى بهدقت I + . • •رم انجام شد. دادههاى حاصل از آزمايش با نرمافزار SAS

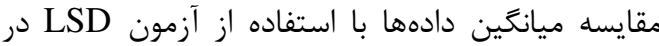
سطح احتمال خطاى ه درصد انجام شد.

نتايج و بحث رشد گياهجه وزن تر و خشك گَياهجه

اثرات اصلى شورى و اسيد هيوميك بر وزنتر و و خشك گياهجه در سطح احتمال ا درصد معنى دار بود. همجنين در بين برهمكنش شورى و اسيد هيوميك در سطح احتمال خطاى ا درصد بر وزن خشك گياهجه و در سطح ه درصد بر وزنتر گياهجه و برهمكنش شورى، اسيد جاسمونيك و اسيد هيوميك در سطح ا درصد بر وزنتر و خشك زياهجه معنى توجه به مقايسه ميانگين برهمكنشها، بيشترين وزنتر

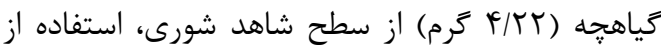

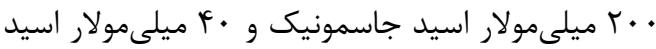

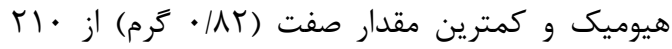

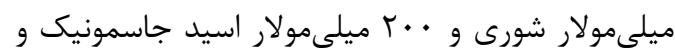

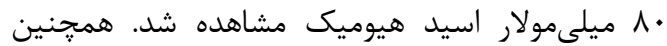
بيشترين وزن خشك زياهجه از سطح شاهد شورى، • ه

\footnotetext{
${ }^{1}$ Primary root length (PRL)

${ }^{2}$ Priming stem length (PSL)

${ }^{3}$ Seedling Fresh waight (SfW)

${ }^{4}$ Seedling dry waight (SDW)
} 
آزاد و همكاران: مطالعه اثر اسيد جاسمونيك و اسيد هيوميك بر برخى شاخصهاى جوانهزنى...

جدول ا- تجزيه واريانس شاخصهاى جوانهزنى جاى ترش تحت تنش شورى، اسيد جاسمونيك و اسيد هيوميك

\begin{tabular}{|c|c|c|c|c|c|c|c|c|c|}
\hline \multicolumn{8}{|c|}{ ميانگين مربعات } & \multirow[b]{2}{*}{ آزادى } & \multirow[b]{2}{*}{ منابع تغيير } \\
\hline شاخص وزنى & طاخص & كياهجه & جوانهزنى درصد & سول & ريشه קه & وزياهجه خشك & وزياهجه & & \\
\hline . TYTYV & $r q / / r^{* * *}$ & $1 \% / 0 \cdot 4^{* *}$ & TY/TFV** & $11 / \Delta \cdot r^{* * *}$ & $r / V \Delta \cdot{ }^{* *}$ & $\cdot / 1991^{* * *}$ & $1 /\left.\wedge \vee\right|^{* *}$ & r & شورى \\
\hline$\cdot / \cdot V r^{\mathrm{ns}}$ & $1 / 1 e^{\mathrm{ns}}$ & $1 / K \varepsilon \Lambda^{*}$ & $1 / 1 / r^{* *}$ & $\cdot(\Delta) \Lambda^{\mathrm{ns}}$ & $1 / 199^{* *}$ & $\cdot / \cdot 18^{\mathrm{ns}}$ & $\cdot / \cdot V \Lambda^{\mathrm{ns}}$ & r & اسيد جاسمونيك \\
\hline$\cdot / \cdot V Y r^{* * *}$ & $1 \cdot 1 \Delta \mathrm{V}^{* *}$ & $f / \mid f f^{* * *}$ & $\varphi / \Delta q V^{* *}$ & $1 / \wedge \Delta \Delta^{* *}$ & $1 / 49 r^{* *}$ & $.1 .9 T r^{* *}$ & $\cdot / \mathrm{A} \cdot \cdot^{* *}$ & r & اسيد هيوميك \\
\hline " & $1 / \pi 18^{\mathrm{ns}}$ & $1 / \Delta \varphi \cdot{ }^{* *}$ & . & $. / 9 .{ }^{* *}$ & $\cdot 1 \Lambda \cdot 0^{* *}$ & $\cdot / \cdot 9 \Delta^{\mathrm{ns}}$ & $\cdot / 1 \cdot \mathrm{r}^{\mathrm{ns}}$ & 9 & شورى×جاسمونيك \\
\hline . $/ \cdot r r r^{* * *}$ & $4 / \cdot q^{*}$ & $1 / \pi 11^{*}$ & $r / T G Y^{* * *}$ & $\cdot / M F \Lambda^{n s}$ & $\cdot \mid r 91^{*}$ & $\cdot / \cdot r q r^{* * *}$ & $\cdot / 19 r^{*}$ & 4 & شورى×هيوميك \\
\hline $.1 .14 q^{*}$ & $1 / 4 \cdot{ }^{\mathrm{ns}}$ & $.1911^{*}$ & $1 /$ TAF* & $\cdot / V \Delta \cdot{ }^{*}$ & $\cdot / \wedge 9^{\mathrm{ns}}$ & $\cdot 1 \cdot 1 \cdot 4^{\mathrm{ns}}$ & $\cdot / \mu c^{n s}$ & 4 & جاسمونيك×هيوميك \\
\hline$\cdot / \cdot 19 V^{* *}$ & $1 /\left.\Delta\right|^{\mathrm{ns}}$ & $\cdot|\Delta S|^{\mathrm{ns}}$ & $.191 r^{*}$ & $\cdot /$ fq. $^{\mathrm{ns}}$ & $\cdot|r V|^{* *}$ & $\cdot 1 \cdot 1 V q^{* * *}$ & $\cdot / 19 r^{* *}$ & 11 & شورى×جاسمونيك× \\
\hline$\cdot 1 \cdot \Delta \phi$ & $1 / \Delta \wedge F$ & $\cdot / 4 \cdot V$ & $\cdot|f| f$ & $\cdot / r \wedge \Delta$ & $.|| r \mid$ & $\cdot 1 \cdot \Delta \Delta$ & .1 .90 & 94 & خطا \\
\hline $1 N / T \Delta$ & $14 / 19$ & $1 \cdot / \pi F$ & $\mathrm{~V} / \wedge \Delta$ & $11 / \mathrm{V}$. & N/RT & $10 / r q$ & IVITY & & ضريب تغييرات (در \\
\hline
\end{tabular}

عامل اصلى افزايش رشد ريشهجه در كياهجه

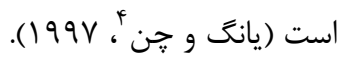

جاسموناتها در رشد و نمو و واكنش به تهنش تنشهاى محيطى نقش تنظيم كنندهاى را ايفا مى كنند. در همين

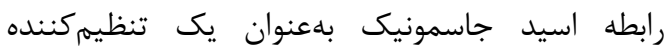

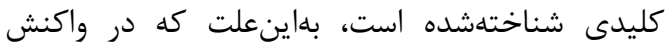

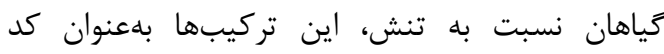
كنندهى زنهاى بازدارنده نظير يروتئينهاى تئونين، اسموتين، هيدروكسى يرولين و رولين و همجنين آنزيمهاى دخيل در بيوسنتز فلاونوئيد در نظر گرفته

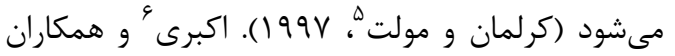

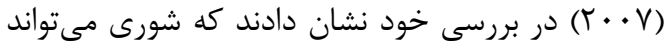
سبب كاهش طول ريشهجه يا ساقهُ كاهش طول گياهجه شود. به نظر مىرسد آمادهسازى بذر با اسيد هيوميك به علت تغييرات متابوليكى و

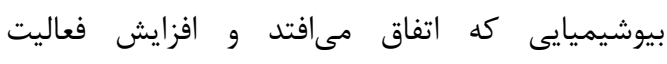

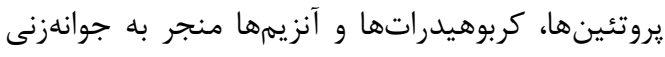

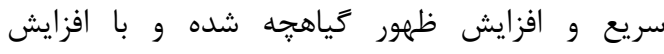
متابوليسم و نفوذيذيرى سلولها نسبت به آب و مواد

${ }_{5}^{4}$ young and Chen

${ }^{5}$ Creelman and Mullet

${ }^{6}$ Akbari
با توجه به برهمكنش سهجانبه؛ بالاترين (4/MFr

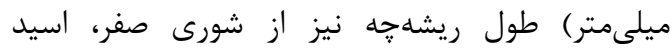

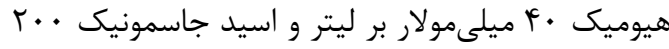

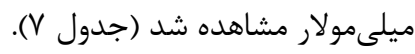

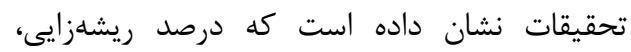
حداكثر و متوسط طول ريشهجه با افزايش غلظت كلريد سديم در نعناع كاهش مىيابد (طبائى عقدايى و

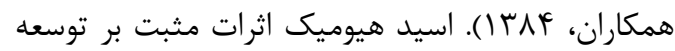
ريشه دارد. بهطورى كه نسبت ريشه به شاخه را افزايش و باعث توليد ريشههاى نازك جانبى در برخى زياهان

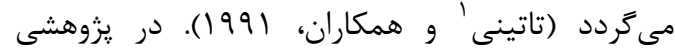
محلولياشى اسيد هيوميك روى جاى ترش سبب بهبيود رشد ريشه و منجر به جذب بالاتر مواد غذايى توسط

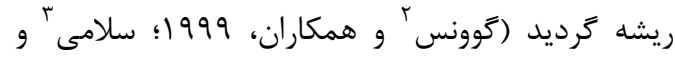

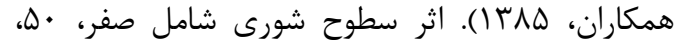

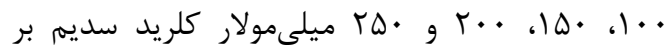
خصوصيات مورفولوزى زيره سبز و سنبلالطيب رال موردمطالعه قراردادند. نتايج نشان داد كه اثر شورى كورى

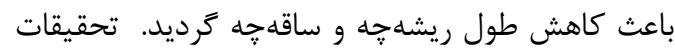
همجنين نشان داد كه تركيبات نيتروزنى اسيد هيوميك ئه

\footnotetext{
${ }^{1}$ Tattini

${ }^{2}$ Guvence

${ }^{3}$ Salami
} 


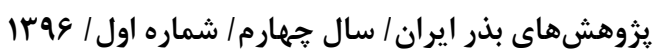

جدول ץ- ادامه تجزيه واريانس شاخصهاى جوانهزنى خاى ترش تحت تنش شورى، اسيد جاسمونيك و اسيد هيوميك

\begin{tabular}{|c|c|c|c|c|c|c|c|}
\hline \multicolumn{6}{|c|}{ ميانگين مربعات } & \multirow[b]{2}{*}{ آزادى درجه } & \multirow[b]{2}{*}{ منابع تغييرات } \\
\hline لازم •و جدوسط زمان & لازم • له درسط زمان & لازم • إ درسط زمان & جكنواخهنى & جوانهزنى & طول ساقه ريه & & \\
\hline$F r / 99^{* *}$ & $r T / V T^{* *}$ & $19 / 99^{* *}$ & $r q / \wedge V^{* * *}$ & $\cdot / \cdot r V r^{* *}$ & $\cdot / r<q^{n s}$ & r & شورى \\
\hline $1 / r r^{n s}$ & $r / 99^{* *}$ & $1 / r \varphi^{\mathrm{ns}}$ & $1 / r \Lambda^{\mathrm{ns}}$ & $. / \ldots+q^{* * *}$ & $. \mid \cdot 9)^{\mathrm{ns}}$ & r & اسيد جاسمونيك \\
\hline$F / T \Lambda^{n s}$ & $\mathrm{~V} / 9 \mathrm{r}^{* * *}$ & $\varepsilon / r \Delta^{* *}$ & $1 / 4 q^{n s}$ & $\cdot 1 \cdot 99^{* *}$ & $\cdot / 1 \cdot \wedge \Delta^{\mathrm{ns}}$ & r & اسيد هيوميك \\
\hline$r|q|^{\mathrm{ns}}$ & 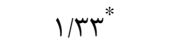 & $1 / \pi \cdot{ }^{\mathrm{ns}}$ & $r / 9 r^{n s}$ & $\cdot 1 \cdot \cdot 10^{\mathrm{ns}}$ & $\left.\cdot|| r \wedge\right|^{\mathrm{ns}}$ & 9 & شورى×جاسمونيك \\
\hline$r / r r^{n s}$ & $1 / 99^{*}$ & $r / 99^{* *}$ & $1 / 9 \Lambda^{\mathrm{ns}}$ & $\cdot 1 \cdot \cdot r^{n s}$ & $\cdot / r q r^{\mathrm{ns}}$ & 4 & شورى×هيوميك \\
\hline$r / \cdot 4^{\mathrm{ns}}$ & $1 / 19^{* *}$ & $r / r r^{*}$ & $1 / \wedge r^{n s}$ & $\cdot / \cdot \mid r^{*}$ & $\cdot / \pi \mid r^{\mathrm{ns}}$ & 4 & جاسمونيك×هيوميك \\
\hline$r / f r^{n s}$ & $1 / \cdot 1^{*}$ & $1 / \cdot v^{\mathrm{ns}}$ & $r / 9 \Delta^{\mathrm{ns}}$ & $\cdot / \cdot \mid r^{\mathrm{ns}}$ & $\cdot / \mu v^{n s}$ & 11 & شورى لجاسمونيك×هيوميك \\
\hline$r / F \wedge$ &.$|9|$ & .199 & T/AT & $\cdot 1 \cdot \cdots v$ &.$/ 1 F \Delta$ & 94 & خطا \\
\hline$I V / F V$ & $1 \mathrm{H} / \mathrm{AN}$ & $\mid r / \cdot F$ & $19 / 1 F$ & $|F / D|$ & IF/QT & - & ضريب تغييرات (./) \\
\hline
\end{tabular}

\section{نسبت طول ساقه}

در مورد اين صفت، تفاوتهاى معنىدارى بين تيمارها وجود نداشت (جدول ب)؛ يعنى هورمونها در اثر ائر

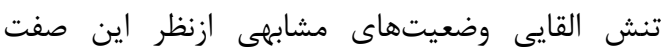

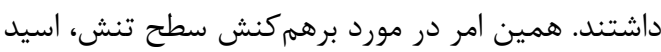
جاسمونيك و اسيد هيوميك نيز صادق بود (جدول ؟).

\section{شاخصهاى جوانهزنى سرعت و درصد جوانهزنى بذر}

نتايج تجزيه واريانس صفات نشان داد كه اثر تنش شورى، اسيد هيوميك و اسيد جاسمونيك و همجنين برهمكنش اسيد جاسمونيك و اسيد هيوميك تأثير معنى دارى در سطح احتمال خطاى ا درصد بر سرعت جوانهزنى در گياه جاى ترش داشت (جدول ؟). درصد

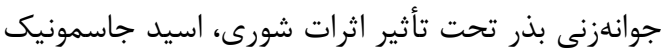
و اسيد هيوميك و برهمكنش شورى و اسيد هيوميك در سطح احتمال خطاى | درصد قرار زرفت. همجنين برهمكنش شورى و اسيد جاسمونيك، اسيد جاسمونيك آن

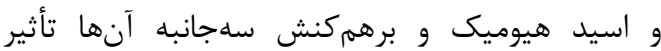
معنى دارى در سطح احتمال خطاى يك درصد بر درصد

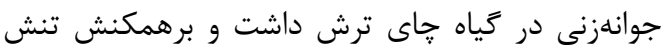
شورى، اسيد جاسمونيك و اسيد هيوميك در سطح احتمال خطاى ه در صد معنى دار بود (جدول ().
غذايى سبب تحريك ريشهزايى مىشود (اصغرىيور و

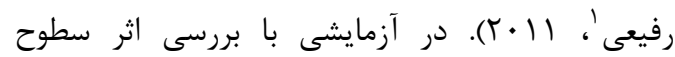

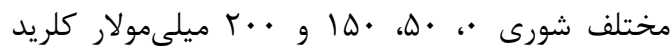

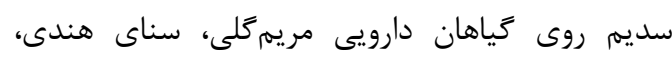
مارتيغال، خاكشير تلخ، شاهدانه، بابونه آلمانى و بابونه رومى ملاحظه شد كه با افزايش غلظت شورى، دريعا درد

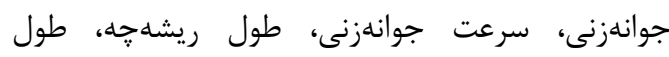
ساقه جه وزن خشك، بنيه بذر و نسبت طول ساقه

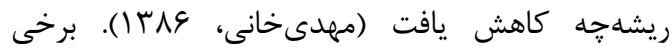
محققان اعلام كردند كه در شرايط تنش، رشد ساقهجه بيشتر از رشد ريشه كاهش مىيابد، اما برخى معتقدند كه تنش، طول

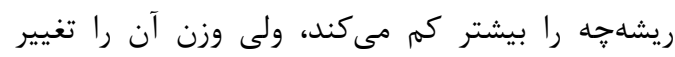

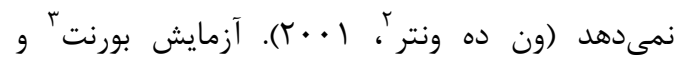

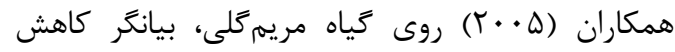
طول ريشه קه و ساقهجه با افزايش شدت تنش اسمزى

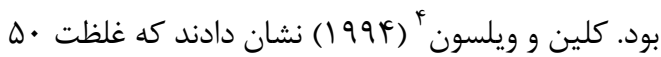
• له ميلى

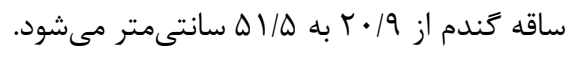

\footnotetext{
${ }^{1}$ Asgharipour and Rafiei

${ }^{2}$ Van de Venter

${ }^{3}$ Burnett

${ }^{4}$ Kline and Wilson
} 
غلظت حدود ·9 ميلىمولار، جوانهزنى بذور اين كيـاه رائ

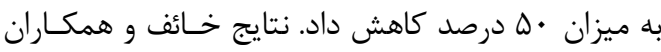
(r (1) نشان داد كه بالاترين درصد جوانهزنى اسـتبرق

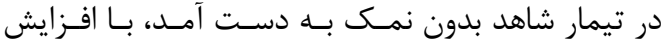

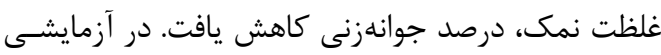
كزارش كردند كه با افزايش سطح تنش اسمزى، درصد و وراني

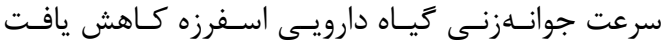

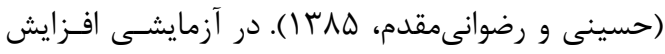
شورى تا F دسى زيمنس بر متر اثر معنى دارى بر درصد

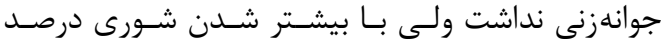

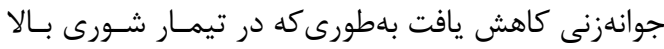

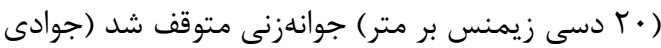
و همكاران، سو بـ (). از طرفى نتايج نشان داده كه كاربرد

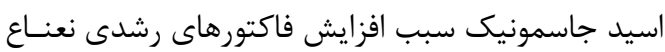
فلفلى شده و مى تواند در افزايش مقاومت نسبت به تنش شورى نقش داشته باشد (حسـينى و همكـاران، بوجس (1).

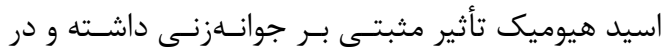
تيمارهاى تنش سبب افزايش جوانهزنسى شـده اسـتـ در در

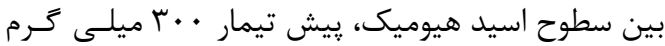
در ليتر در سطوح تنش بالا نسبت بـهـ سـاير تيمارهـا در دئس اكثر صفات موردمطالعه برترى داشت. در مجمـوع نتـايج

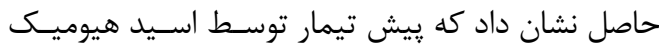
مى تواند باعث مقاومت بذر در مرحله جوانه زنى و استقرار

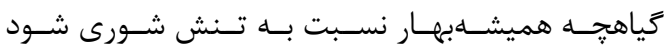

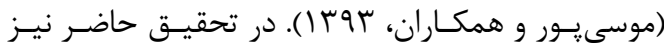

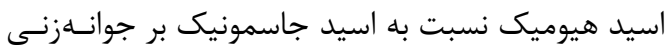

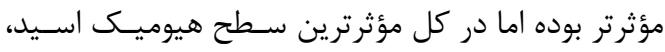

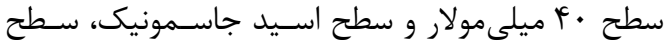

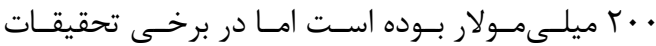

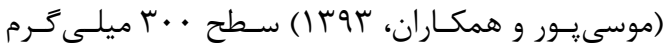
هيوميك مؤثرترين بوده كه با تحقيق حاضر متفاوت بوده و مىتوان مهمترين نقش را نوع كياه موردنظر دانست.

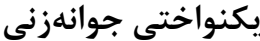

با توجه به جدول تجزيه واريانس (جدول ؟) اثر تنش شورى بر صفت يكنواختى جوانهزنى در سطح احتمال خطاى 1 درصد معنىدار شد؛ و وبنى بقيه اثرات معنى دار نبودند. بررسى صفت يكنواختى جوانهزنى در
مقايسه ميـانگين سـرعت جوانسهزنسى نشـان داد، در تيمار تنش شورى، بيشترين سرعت جوانهزنى، در شرايط

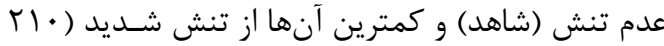

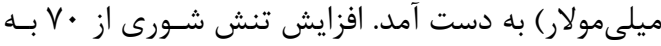

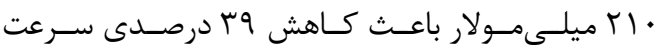

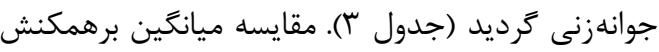

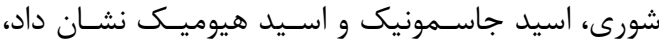
بيشترين درصد جوانهزنسى جـاى تـرش از سـطح شـاهد

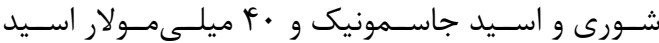

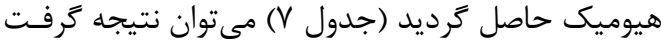
برهمكنش اسيد جاسمونيك و اسيد هيوميك نمىتوانسد اثر شورى را از بين ببرد. جوانهزنى بذرها بخش حساسى از مراحل نمو كياهى

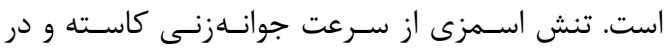
تنشهايى كه شدت آنها زياد است هم ميزان جوانهزنى

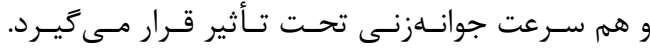

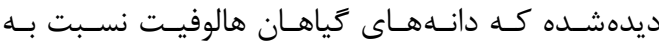
كليكوفيتها مقاومت بيشترى به شورى دارند. در شورى

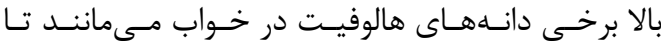

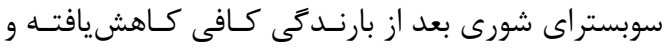

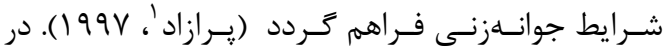
آزمايشى روى جهار كونه گيـاهى (سـياهدانـه، شـاهدانه،

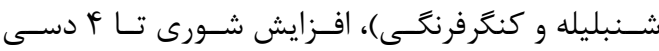
زيمنس بر متر اثر معنىدارى بر درصد جوانهزنى نداشت، ولى با بيشتر شدن شورى درصد جوانهزنى كاهش يافت؛

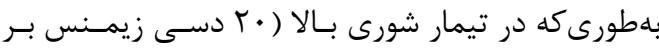

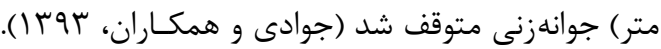
كزارشهايى از افزايش درصد و سرعت جوانهزنى با متيل

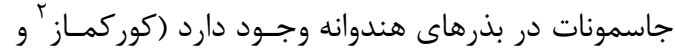

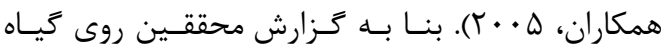

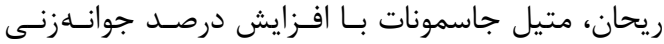

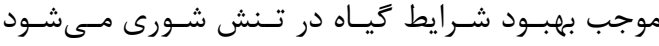

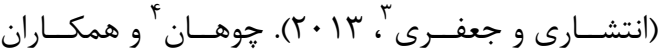

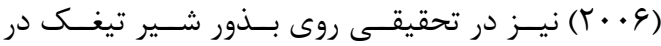

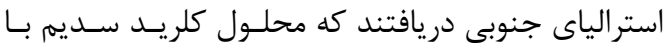

\footnotetext{
${ }^{1}$ Prasad

${ }^{2}$ Korkmaz

${ }^{3}$ Enteshari and Jafary

${ }^{4}$ Chauhan
} 
تنش شورى شد (رضايى ' و همكاران، سا • r). همجنين

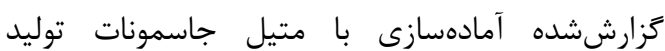
يلى آمين آزاد را در بافتهاى گياهى تحريك مى كند؛ بنابراين متيل جاسمونات و يلى آمين بلهورت همرافزايى عمل مى كنند و آمادهازى بذر با متيل جاسمونات درصد و سرعت جوانهزنى و ظهور زياهجه را افزايش

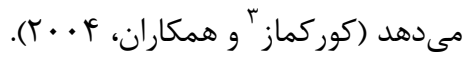

كزارشهايى از اثر افزايشى درصد و سرعت جوانهزنى هونى

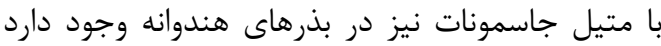

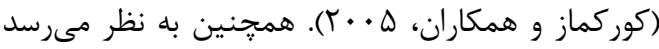

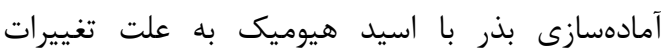

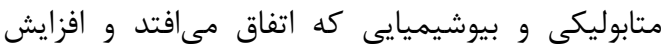

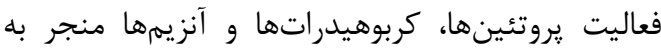
جوانهزنى سريع و افزايش ظهور گياهجه شده و و بان افزايش متابوليسم و نفوذيذيرى سلولها نسبت به آب و و مواد غذايى سبب تحريك ريشهزايى مىشود (مقبلى و

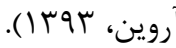

در تحقيقى اثر آمادهسازى بذر با تنظيمكنندههاى رشد (اسيد هيوميك، اسيد جاسمونيك و و اسيد ساليسيليك) بر خصوصيات جوانهزنى، رشد و عملكرد ميوه طالبى مورد ارزيابى قراركرفته كه بيشترين ميزان درصد و سرعت جوانهزنى در آمادهسازى با اسيد

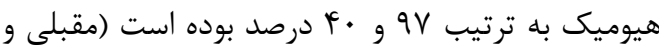

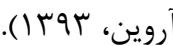

شاخص هاى بنيه بذر شاخص طولى و وزنى بنيه

شاخص طولى و وزنى بنيه تحت تأثير اثرات شورى و اسيد هيوميك در سطح احتمال خطاى 1 درصد قرار كرفتند. برهمكنش شورى و اسيد جاسمونيك، اسيد جاسمونيك و اسيد هيوميك تنها بر شاخص وزنى بنيه (در سطح احتمال خطاى ه درصد) و برهمكنش شورى و اسيد هيوميك بر هر دو صفت معنى دار شد. همجنين

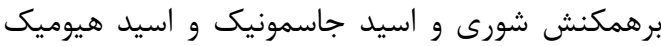
تنها بر شاخص وزنى بنيه در سطح احتمال خطاى 1 درصد معنى دار شد (جدول ( ).

\footnotetext{
${ }^{2}$ Rezaei

${ }^{3}$ Korkmaz
}

سطوح مختلف شورى نشان داد كه با افزايش شورى از ميزان يكنواختى جوانهزنى كاسته شد (در شورى صفر بـ بيشترين ميزان و در شورى • إ ميلىمولار كمترين ميزان به دست آمد) (جدول ؟). در يكنواختى جوانهزنى هر جقدر مطلق عدد بهدستآمده كمتر باشد نشاندهنده اين است كه يكنواختى جوانهزنى بيشتر است (سلطانى و

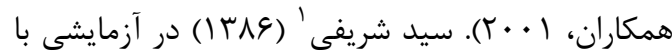

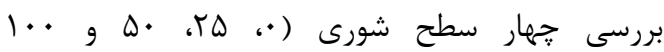
ميلىمولار) كلريد سديم بر جوانهزنى مارتيغال نشان داد كه تنش شورى اثر معنى دارى بر يكنواختى جوانهزنى داشت.

متوسط زمانهاى لازم براى جوانهزنى نتايج تجزيه واريانس صفات نشان داد، اثر اسيد جاسمونيك تنها بر زمان لازم براى • له درصد جوانهزنى دئى معنىدار شد. اثر اسيد هيوميك بر زمان لازم براى • 1 و • ه درصد جوانهزنى و اثر شورى بر هر سه سف صفت معنى دار شد. برهمكنش شورى و اسيد جاسمونيك تنهها

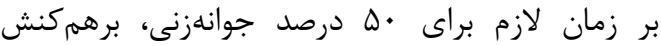
شورى، اسيد هيوميك و اسيد جاسمونيك و اسيد

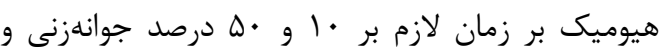
برهمكنش سهجانبه تنها بر زمان لازم بر له له درصد جوانهزنى معنى دار شد (جدول ب). مقايسه ميانگين

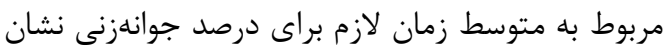
داد، سطح صفر تنش يا شاهد كمترين و تنش شورى

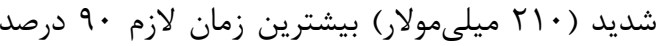

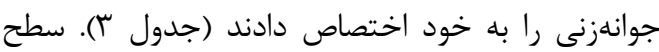

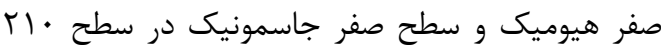
ميلىمولار شورى، بيشترين زمان لازم •ه درصد

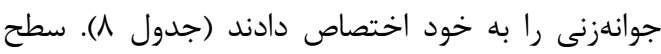

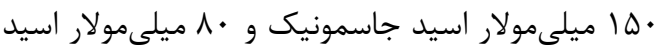

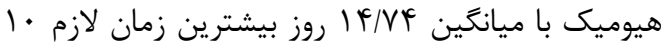
درصد جوانهزنى را به خود اختصاص دادند (جدول ؟). طى ززارشى مشابه خيساندن بذر فلفل در محلول متيل جاسمونات با غلظت · له ميلى گرم در ليتر، سبب افزايش درصد جوانهزنى و بهبود استقرار دانهالها تحت

\footnotetext{
${ }^{1}$ Sayed Sharifi
} 
آزاد و همكاران: مطالعه اثر اسيد جاسمونيك و اسيد هيوميك بر برخى شاخصهاى جوانهزنى...

\begin{tabular}{|c|c|c|c|c|c|}
\hline \multicolumn{6}{|c|}{ جدول r - مقايسه ميانكين اثرات اصلى تنش شورى، اسيد جاسمونيك و اسيد هيوميك براى شاخصهاى جوانهزنى خاى ترش } \\
\hline زمان لازم براى • ج درصد جوانهزنى (روز) & $\begin{array}{c}\text { يكنواختى جوانهزنى } \\
\text { (روز) }\end{array}$ & 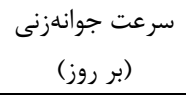 & شاخص طولى بنيه & 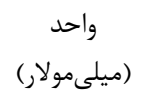 & تيمار \\
\hline $9 \cdot / r \Delta C$ & $\Delta F / I T C$ & $\cdot 1 \cdot \Delta r a$ & $4 \vee / 99 \mathrm{a}$ & . & \multirow{4}{*}{ شورى } \\
\hline$\vee १ / q) b$ & $V y / \cdot V b$ & $\cdot / \cdot r \wedge b$ & r)/६६b & $\checkmark \cdot$ & \\
\hline$q \cdot / 9 \mathrm{rb}$ & $\Lambda \cdot / \varepsilon r \mathrm{ab}$ & $\cdot / \cdot r \cdot \mathrm{c}$ & $r \& / 9 \wedge \mathrm{b}$ & if. & \\
\hline $1 \cdot \mathrm{V} / \mathrm{\Delta Va}$ & $91 / \Delta 9 \mathrm{a}$ &.$/ \cdot r \mathrm{rd}$ & $10 / 99 \mathrm{c}$ & r). & \\
\hline 19/4ra & $\Lambda \cdot / v \varepsilon a$ & $\cdot 1 \cdot r \cdot a$ & r1/99a & . & \multirow{4}{*}{ اسيد جاسمونيك } \\
\hline$\Lambda \Delta / \vee \cdot a$ & VQ/Tra & $\cdot 1 \cdot f \cdot a$ & $r / / \perp \Delta a$ & $\Delta \cdot$ & \\
\hline$\Lambda F / .9 a$ & $\mathrm{vr} / \mathrm{lla}$ & . & $r \cdot 1 \Delta \varphi \mathrm{a}$ & 10. & \\
\hline $\mathrm{Vq/9} \mathrm{ra}$ & $V \backslash / r \backslash a$ & $\cdot / \cdot r \cdot b$ & TN/TYa & r.. & \\
\hline $9 \cdot / 19 a$ & $V \wedge / r \Delta a$ & $\cdot 1 \cdot r q b$ & $r \Delta / 4 \Leftrightarrow \mathrm{b}$ & . & \multirow{3}{*}{ اسيد هيوميك } \\
\hline$\vee 9 / 99 a$ & $V Y / r V a$ & $.1 .49 a$ & re/fra & f. & \\
\hline $11 / 1 \varepsilon a$ & $V F / \Delta V a$ & $\cdot 1 \cdot r \cdot a$ & rq/q rab & $\Lambda$. & \\
\hline \multirow{2}{*}{\multicolumn{6}{|c|}{ نر هر ستون و هر تيمار، حروف مشابه نمايانكر عدم اختلاف معنىدار بر اساس آزمون LSD در سطح احتمال خطاى ينج درصد است. }} \\
\hline & & & & & \\
\hline \multirow{2}{*}{ طول كياهجه (ميلىمتر) } & \multirow{2}{*}{ طول ساقه ֶه (ميلىمتر) } & \multicolumn{4}{|c|}{ تيمار } \\
\hline & & (مولار) & جاسمونيك اسيد (ميلك & مولار) & شورى (ميلك \\
\hline FN/AIab & $r \Delta / v \Delta a-c$ & & . & \\
\hline rq/lVe-g & $r F / r F b-d$ & & $\omega \cdot$ & & \\
\hline$F r / q F b-e$ & re/fra-c & & 10. & & \\
\hline$\Delta r / \varphi / a$ & rq/६ra & & $r \cdot$. & & \\
\hline $\mathrm{F} \wedge / \cdot \wedge \mathrm{a}-\mathrm{c}$ & rV/rqab & & . & \multirow{4}{*}{\multicolumn{2}{|c|}{$v$. }} \\
\hline fl/fre-f & $r F / f r b c$ & & $\Delta \cdot$ & & \\
\hline$r r / \Delta r g-j$ & 19/4Ve-g & & 10. & & \\
\hline$r \varepsilon / \& q b-d$ & rF/Arbc & & $r \cdot$. & & \\
\hline rN/ $\cdot \wedge e-h$ & $19 / \cdot \Delta \mathrm{e}-\mathrm{g}$ & & $\cdot$ & \multirow{4}{*}{\multicolumn{2}{|c|}{ if. }} \\
\hline$r \Delta / \Delta \vee f-i$ & $19 / \wedge \Delta \mathrm{e}-\mathrm{g}$ & & $\Delta \cdot$ & & \\
\hline$r \cdot \mid q r d-f$ & 19/4Ve-g & & 10. & & \\
\hline fl/vic-f & rr/Drc-e & & $r \cdot$. & & \\
\hline$r F / \Lambda / k$ & $11 / r$ fh & & · & \multirow{4}{*}{\multicolumn{2}{|c|}{ r). }} \\
\hline$r \mathrm{I} / \mathrm{s} \mathrm{h}-\mathrm{k}$ & $\mid \varepsilon / \pi \hookrightarrow f g$ & & $\omega \cdot$ & & \\
\hline$r \nu / \cdot r i-k$ & IV/Vrfg & & 10. & & \\
\hline$r V / V r j k$ & $10 / 4 r g h$ & & $r \cdot$. & & \\
\hline
\end{tabular}


يزوهشهاى بذر ايران / سال جهارم/ شماره اول / وجسا

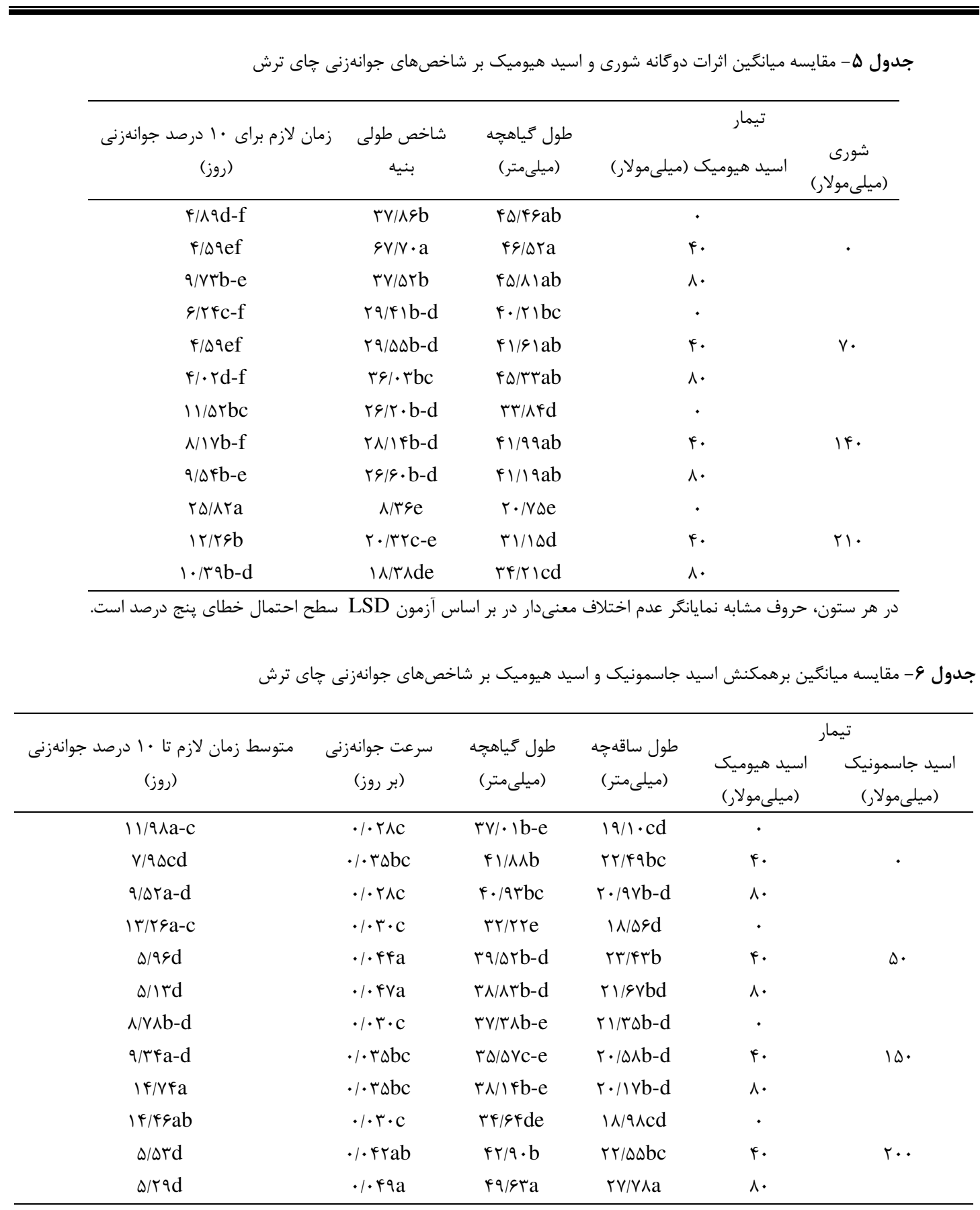

در هر ستون، حروف مشابه نمايانكر عدم اختلاف معنى دار بر اساس آزمون LSD در سطح احتمال خطاى ينج درصد است.

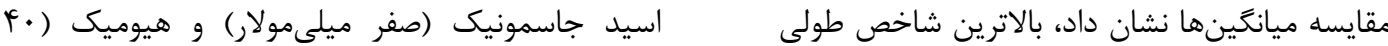

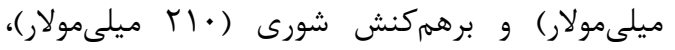

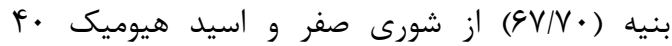
جاسمونيك (صفر ميلىمولار) و اسيد هيوميك (صفر آندان

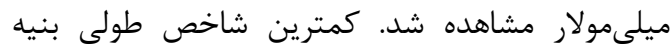
ميلىمولار) به دست آمد (جدول ^).

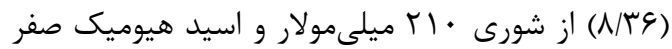
بلهدست آمد (جدول ه). بالاترين و وِايينترين شاخص وزنى به ترتيب از برهم كنش شورى (صفر ميلىمولار)، 
جدول V- مقايسه ميانكَين برهمكنش تنش شورى، اسيد جاسمونيك و اسيد هيوميك بر شاخصهاى جوانهزنى جاى ترش

\begin{tabular}{|c|c|c|c|c|c|c|c|c|c|c|c|c|c|}
\hline \multirow{2}{*}{\multicolumn{3}{|c|}{ اسيد هيوميكى (ميلى موانهنى (درصد) }} & \multirow{2}{*}{\multicolumn{3}{|c|}{ طول ريشه جه (ميلىمتر) }} & \multirow{2}{*}{\multicolumn{3}{|c|}{ اسيد هيوميك (ميلى خولار) }} & \multirow{2}{*}{\multicolumn{3}{|c|}{ اسيد هيوميك (ميلى مولار) }} & \multirow{2}{*}{\multicolumn{2}{|c|}{ تيمار }} \\
\hline & & & & & & & & & & & & & \\
\hline$\wedge$. & f. & - & $\Lambda$. & r. & • & $\Lambda$. & r. & • & $\wedge$. & $r$. & $\cdot$ & جاسمونيك & (ميلىمولار) \\
\hline$\Lambda r / 49 a-d$ & $9 \mathrm{~T} / \cdot \cdot \mathrm{a}$ & $\Lambda r / 94 a-d$ & $r \Delta / r \cdot a b$ & rr/Ara-d & $r \mid / / r b-g$ & $\cdot / \pi \Delta a-e$ & $\cdot / q \cdot a b$ & $\cdot / r a b-k$ & r/q a-c & $r / r v a-f$ & r/Tad-o & . & \\
\hline VV/rra-g & ^ı/rra-e & $\Lambda \cdot / \cdot \cdot \mathrm{a}-\mathrm{f}$ & IV/vie-m & $r \cdot / 1 \cdot c-i$ & $|f /| \gamma l-p$ & $\cdot / r r g-n$ & $\cdot / r \cdot a-j$ & . /rra-g & $r / \omega \cdot c-n$ & $r / \Delta r b-m$ & $r / 9 \vee b-k$ & $\Delta \cdot$ & \\
\hline$q 4 / \cdot f \mathrm{f}-\mathrm{m}$ & $\Lambda \Delta / r r a-c$ & VN/99a-g & $19 / 9 \cdot f-n$ & IV/r & rr/D\&a-d & $\cdot / r k f-n$ & $\cdot / 4 \mid \mathrm{a}$ & $\cdot / r a b-k$ & $r / Y r d-p$ & $r / \Delta r a-d$ & $r / r q a-f$ & 10. & \\
\hline $9.199 \mathrm{ab}$ & $\wedge \mathrm{s} / \cdot \cdot \mathrm{a}-\mathrm{c}$ & $\Lambda \Delta / \mathrm{rra}^{\prime} \mathrm{a}$ & rr/gra-d & $r g / r f a$ & rr/q६a-d & $\cdot / r \Delta a-f$ & $\cdot / r v a-d$ & $\cdot / r r g-0$ & r/v ab & f/rra & $1 / 9 \vee g-s$ & $r .$. & \\
\hline$\Lambda r / 49 a-d$ & $\mathrm{~V} \cdot 199 \mathrm{c}-\mathrm{k}$ & VN/99a-g & $r \mid / f \Delta b-f$ & 19/9 De-n & $r r / 99 \mathrm{a}-\mathrm{c}$ & $\cdot / r v c-m$ & $\cdot / \pi \cdot a-c$ & $\cdot / \pi q a-e$ & r/lVa-g & r/fla-e & $r / \Delta / a-d$ & . & \\
\hline 11/rra-e & GQ/Tre-1 & $\Lambda \cdot / \cdot \cdot \mathrm{a}-\mathrm{f}$ & 19/9vc-g & |N/V9d-1 & $\mid r / r V d-q$ & . rse-m & $\cdot / r \mid a-i$ & $\cdot /$ raa-g & $r / r \Delta a-e$ & 1/9 Yh-s & $r / r \Delta d-p$ & $\Delta \cdot$ & \\
\hline $\mathrm{V} \cdot 199 \mathrm{c}-\mathrm{k}$ & $V r / r r c-i$ & $\varphi \Delta / r r \mathrm{e}-1$ & $\mid \Delta / \backslash \Delta j-p$ & $1 r / r r m-q$ & $\mid r / \Lambda \cdot m-p$ & /rra-h & $\begin{array}{c}\cdot r \varepsilon \mathrm{d}- \\
\mathrm{m}\end{array}$ & $\cdot / r V c-1$ & $r / / r f-q$ & $r / Q \cdot c-n$ & $r / r \wedge e-p$ & 10. & V. \\
\hline$\Lambda \cdot / \cdot \cdot \mathrm{a}-\mathrm{f}$ & $V r / r r c-i$ & $9 N / \cdot \cdot d-1$ & $r r / q \cdot a-c$ & $r \cdot \mid q \Delta b-h$ & $r \cdot / v / b-h$ & $\cdot / r \wedge c-k$ & $\cdot / r r g-o$ & $\cdot r \cdot a-j$ & $r / .9 a-h$ & $r / F q c-n$ & $r / \Lambda \Upsilon \mathrm{b}-\mathrm{j}$ & $r \cdot$. & \\
\hline$q 4 / \cdot \cdot \mathrm{f}-\mathrm{m}$ & $\Delta N / 9 \notin \mathrm{h}-\mathrm{o}$ & fa/rrno & $19 / \cdot c-k$ & $r \cdot 1 \cdot 9 \mathrm{c}-\mathrm{i}$ & $\mid q / \pi \Delta h-0$ & $\cdot / r \varepsilon \mathrm{d}-\mathrm{m}$ & $\cdot / / r \mathrm{n}-\mathrm{r}$ & $\cdot / / \wedge k-p$ & $r / \cdot b \mathrm{~b}-\mathrm{i}$ & $1 / r F m-t$ & $1 / \pi 90-t$ & . & \\
\hline $9 \pi / 99 \mathrm{~g}-\mathrm{m}$ & $\Delta F / \& \& \mathrm{k}-\mathrm{O}$ & $\Delta s / \cdot \cdot \mathrm{j}-\mathrm{o}$ & $\mid f / 4 \& k-p$ & IV/ree-m & $|q /| r h-p$ & $\cdot / / r \mathrm{n}-\mathrm{r}$ & $\cdot / / \mathrm{Vl}-\mathrm{q}$ & $\cdot / / \vee l-q$ & $1 / \pi r n-t$ & r/lra-g & $1 / 4+1-t$ & $\Delta \cdot$ & \\
\hline$s q / \cdot \cdot \mathrm{f}-\mathrm{m}$ & $V \cdot 199 \mathrm{c}-\mathrm{k}$ & $9 \mathrm{~N} / \cdot \cdot \mathrm{d}-1$ & rr/rra-d & $r \mid / v \cdot a-e$ & $19 / \Delta 9 c-j$ & /rra-h & $\cdot / r \gamma c-1$ & $\begin{array}{c}\cdot / r \varepsilon \mathrm{d}- \\
\mathrm{m}\end{array}$ & $1 / v r j-t$ & $1 / \wedge \mid \mathrm{i}-\mathrm{t}$ & 1/^9h-s & 10. & If. \\
\hline$V Y / \cdots c-j$ & $\Lambda r / 49 \mathrm{a}-\mathrm{d}$ & $4 \cdot / \cdot \cdot h-n$ & rr/fVa-d & $r \cdot / \wedge \mid b-h$ & 19199f-o & $\cdot \pi s \mathrm{e}-\mathrm{m}$ & / /rra-g & $\cdot / r \mid h-p$ & $r / 9 r \mathrm{~b}-1$ & r/rra-f & $1 / \Delta \Delta \mathrm{k}-\mathrm{t}$ & $r \cdot$. & \\
\hline $4 \cdot 1 \cdot$ h-n & $V q / 9 \varepsilon b-h$ & rr/\&øp & $|\uparrow /| \& 1-p$ & IV/vie-m & $\mid r / 190-q$ & $\cdot / r i \mathrm{i} p$ & $\cdot / r A c-1$ & $\cdot / \cdot r r$ & I/vaj-t & r/ґra-g & $.94 \mathrm{t}$ & . & \\
\hline$\Delta V / r r i-o$ & $\triangle \mathrm{N} / 99 \mathrm{~h}-\mathrm{O}$ & ${ }^{\prime} \mathrm{N} / \cdot \cdot \mathrm{m}-\mathrm{O}$ & $\mid v / r \cdot e-m$ & $\mid \Delta / f \cdot i-p$ & $\mid r / r a m-q$ & $\cdot / r \cdot i-p$ & $\cdot / r \mid h-o$ & $\cdot / / f n-r$ & r/rse-p & $\mid / \wedge 1 \mathrm{i}-\mathrm{t}$ & $1 / \cdot \Delta q-t$ & $\Delta \cdot$ & r). \\
\hline$\Delta V / r r i-o$ & $\Delta r / T r l-o$ & $F T / 990$ & $\mid 9 / \Delta \wedge \mathrm{h}-\mathrm{O}$ & $|\Delta| \cdot \wedge j-p$ & $11 / \Delta r p q$ & $\cdot / r \cdot i-p$ & $\cdot / / 9 j-p$ & $\cdot / /$ To-r & $r / \cdot r g-r$ & $1 / 9 \Delta \mathrm{j}-\mathrm{t}$ & $1 / 1 \varepsilon \mathrm{p}-\mathrm{t}$ & 10. & $r$ \\
\hline FQ/TTO & $V \psi / q 9 b-h$ & $\Delta r / \cdot \cdot 1-O$ & $\mathrm{IV} / \mathrm{V} \cdot \mathrm{e}-\mathrm{m}$ & $|r / 9| \mathrm{m}-\mathrm{q}$ & N/qrq & $.1 .4 \mathrm{qr}$ & $\cdot / \Gamma \mid a-i$ & $\cdot / / \cdot \mathrm{p}-\mathrm{r}$ & - /Arst & $r / \Delta f b-1$ & $\cdot / \wedge \gamma r-t$ & $r .$. & \\
\hline
\end{tabular}

در هر ستون، حروف مشابه نمايانكر عدم اختلاف معنىدار بر اساس آزمون LSD در سطح احتمال خطاى ينج درصد است.

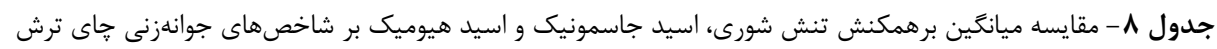

\begin{tabular}{|c|c|c|c|c|c|c|c|}
\hline \multicolumn{3}{|c|}{ متوسط زمان لازم •له درصد جوانهزنى } & \multicolumn{3}{|c|}{ شاخص وزنى بنيه } & \multirow{3}{*}{$\begin{array}{l}\text { اسيد جاسمونيك (ميلىمولار) }\end{array}$} & \multirow{3}{*}{ (ميلىمولار) } \\
\hline \multicolumn{3}{|c|}{ اسيد هيوميك (ميلىمولار) } & \multicolumn{3}{|c|}{ اسيد هيوميك (ميلىىمولار) } & & \\
\hline$\Lambda$. & f. & . & $\Lambda$. & $r$. & . & & \\
\hline$r \varepsilon / \cdots \mathrm{k}-\mathrm{q}$ & rg/frk-q & $r \cdot 1 \cdot \cdot n-q$ & ./ ११а-е & $\cdot / \mathrm{rVa}$ & - /FFC-i & . & \\
\hline$|Q / r| q$ & $\mid Q / 9 \cdot q$ & 19/.ro-q & $\cdot / / \wedge d-1$ & $\cdot /$ FAC-i & $\cdot / r v a-g$ & $\Delta \cdot$ & \\
\hline$q \tau / \cdot \varphi d-j$ & $\mid \mathrm{V} / \cdot \Delta \mathrm{pq}$ & $r \cdot / 9 r m-q$ & $\cdot / / \& \mathrm{i}-\mathrm{p}$ & $\cdot / r \Delta a b$ & $\cdot / r r d-j$ & 10 . & \\
\hline । $1 / \wedge 9 q$ & $\mid q / q \cdot q$ & $r \wedge / q r h-q$ & ./rra-d & $\cdot /$ ra-c & $\cdot / \mathrm{r} \cdot \mathrm{e}-\mathrm{m}$ & $r \cdot$. & \\
\hline$r T / T \cdot g-p$ & $r r / A V m-q$ & r//१८d-1 & $\cdot /$ r d $-\mathrm{k}$ & $\cdot / r \& b-h$ & $\cdot / / q a-f$ & · & \\
\hline$r r / q \hookrightarrow 1-q$ & $r \Lambda / v \cdot h-q$ & rF/Ģe-n & $\cdot / r \mid e-1$ & $\cdot / / \Delta \mathrm{i}-\mathrm{q}$ & $\cdot / r V b-h$ & $\Delta \cdot$ & v \\
\hline rV/Dri-q & $r \Lambda / r \cdot h-q$ & $r \wedge / \cdots \mathrm{i}-\mathrm{q}$ & $\cdot / r \mathrm{rd}-\mathrm{k}$ & $\cdot / r \cdot e-m$ & $\cdot / / V h-o$ & 10. & $v$ \\
\hline$r M / \wedge 9 m-q$ & $r \cdot 199 \mathrm{~m}-\mathrm{q}$ & $r \varepsilon / q r j-q$ & $\cdot / r r d-j$ & $\cdot / / \& \mathrm{i}-\mathrm{p}$ & $\cdot / r \cdot e-1$ & $r \cdot$. & \\
\hline$F \Delta / \wedge r b-g$ & $F r / \cdot \Delta d-j$ & $F \Delta / r r b-g$ & $\cdot / 14 \mathrm{i}-\mathrm{p}$ & $\cdot / \cdot \wedge \mathrm{O}-\mathrm{S}$ & $\cdot / \cdot \wedge \mathrm{O}-\mathrm{S}$ & . & \\
\hline 19/Arn-q & $r r / 99 \mathrm{~m}-\mathrm{q}$ & rq/vra-e & $\cdot / \cdot \wedge \mathrm{O}-\mathrm{S}$ & $\cdot / 1 \& \mathrm{i}-\mathrm{p}$ & $\cdot / \cdot 9 n-s$ & $\Delta \cdot$ & 16 \\
\hline $\mathrm{FV} / \mathrm{r} \cdot \mathrm{b}-\mathrm{g}$ & $\lceil N / \Delta \Delta a-f$ & rq/.·d-1 & $\cdot / 1 \cdot \mathrm{m}-\mathrm{s}$ & $\cdot / 19 f-n$ & $\cdot / / \wedge g-n$ & 10. & 11. \\
\hline$r \cdot / \wedge \vee m-q$ & $r \omega / r \cdot e-m$ & $f \Delta / f r b-g$ & $\cdot / / \wedge \mathrm{g}-\mathrm{n}$ & $\cdot / r \vee b-h$ & $\cdot / / r j-q$ & $r .$. & \\
\hline$\Delta \cdot / 99 \mathrm{a}-\mathrm{d}$ & fr/mb-h & ar/rra & $\cdot / / r l-q$ & $\cdot /$ Trd-k &.$\cdot 9 \mathrm{~s}$ & . & \\
\hline $\mathrm{r} \cdot 19 \cdot \mathrm{d}-\mathrm{k}$ & fV/rrub-g & $\Delta V / \Delta \cdot a-c$ & $\cdot / 1 r \mathrm{k}-\mathrm{q}$ & $\cdot / \mathrm{rk}-\mathrm{r}$ & $\cdot / \cdot v p-s$ & $\Delta \cdot$ & (1). \\
\hline$r F / \cdot \Delta l-q$ & fq/Trb-g & rq/r^a-e & $\cdot / \mid r l-r$ & $\cdot / 1 \cdot \mathrm{m}-\mathrm{s}$ & $\cdot / \cdot \Delta \mathrm{q}-\mathrm{s}$ & 10 & 11. \\
\hline rr/Alf-o & fr/vic-i & $\Delta \wedge / 19 \mathrm{ab}$ & $\cdot / \cdot \operatorname{rrs}$ & •/rrd-i & $\cdot / \cdot \Delta q-s$ & $r .$. & \\
\hline
\end{tabular}


ريشهجه بيشتر است، در نتيجه مشاهده شده كه در حضور

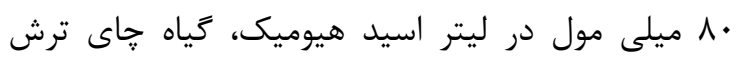

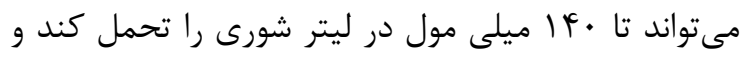

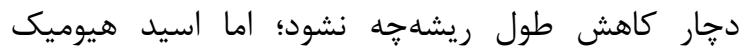

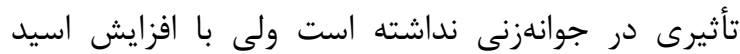

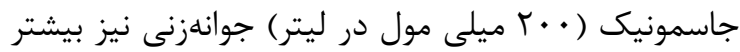
شده از طرفى جون بيشترين ميزان طول ريشه جهاه، وزنتر

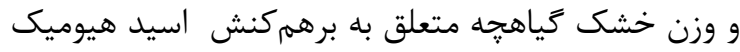
و اسيد جاسمونيك در عدم حضور شورى بوده است.

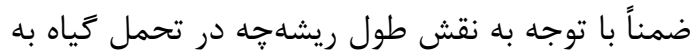
شرايط شورى مىتوان نتيجه ترفت كه استفاده از برهم كنش اسيد جاسمونيك و اسيد هيوميك مىتواند هم

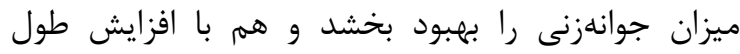

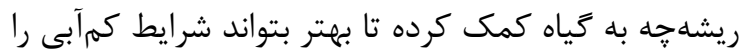
تحمل كند.
نتيجه نتايج آزمايش نشان داد كه بيشترين ميزان درصد

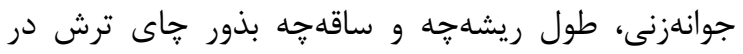

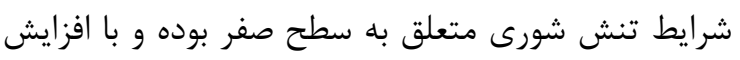
شدت تنش شورى بلتناسب ميزان صفات يادشده كمتر

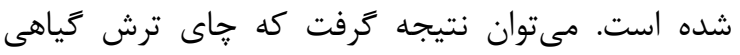

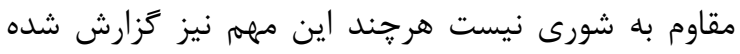

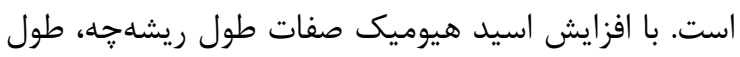

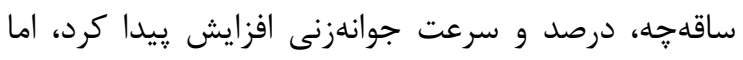

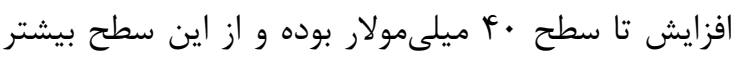

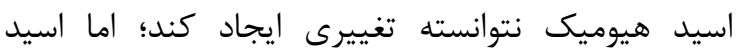

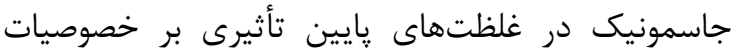

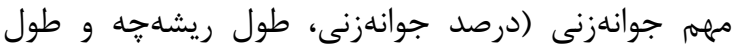

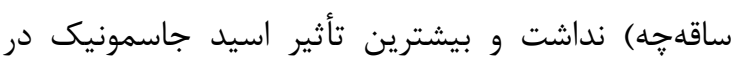

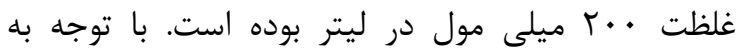

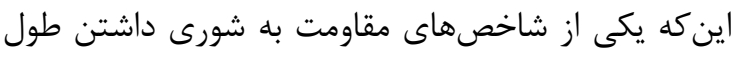

\section{منابع}

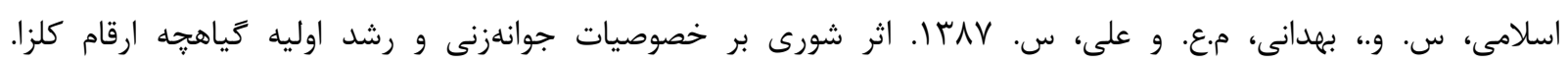
(Brassica napus L.)

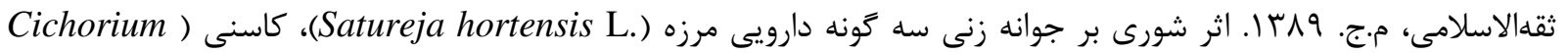
(intybus L.

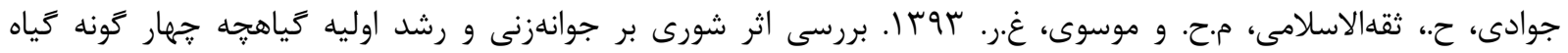

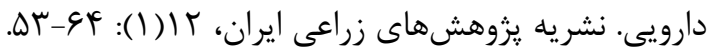

حسينى، ا.ا.، افشارى، ح. و اكبرزاده، م. بوجا، بررسى اثر اسيد جاسمونيك بر برخى صفات فيتوشيميايى و مورفولوزيكى كياه

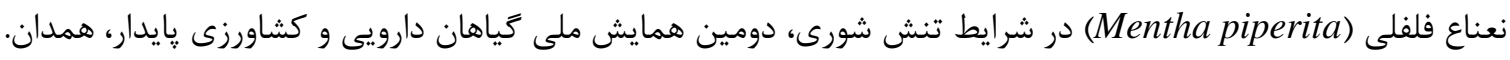
حسينى، ح. و رضوانىمقدم، ״. ضیץ ا. اثر تنش خشكى و شورى بر جوانهزنى اسفرزه (Plantago ovata). مجله يزوهشهاى

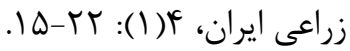

خائف، ن.، انجوى موسوى، ف. و بديهى، ر.س. rوسا. بررسى اثر شورى بر جوانهزنى بذر استبرق (Calotropi procera L.).

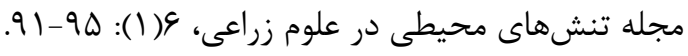

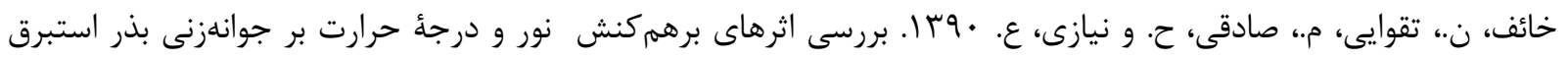
(Calotropis procera L.) خمرى، ع.، سارانى، ش.ا. و دهمرده، م. عیז ا. بررسى تأثير تنش شورى بر جوانهزنى بذر و رشد كياهجه در شش گونه كياه 
دارويى. فصلنامه تحقيقات كياهان دارويى و معطر ايران، س: وسب- اسب.

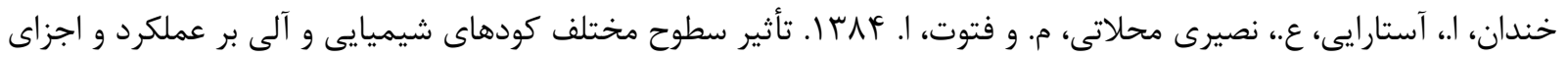

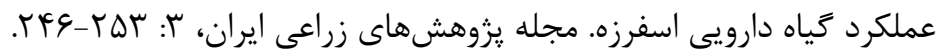

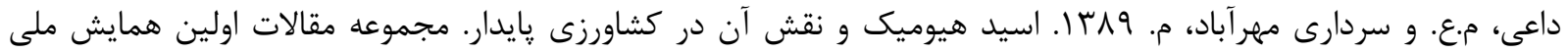

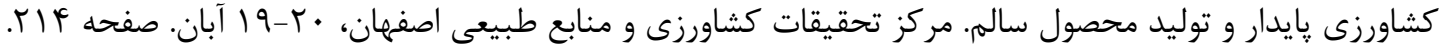

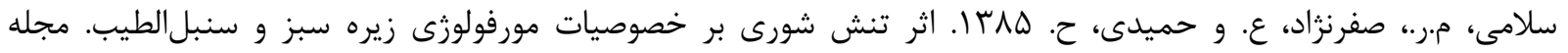

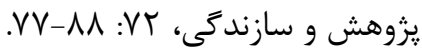

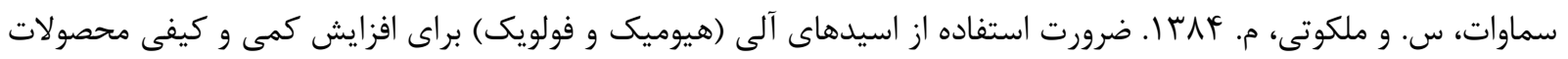
كشاورزى. نشريه فنى، شماره بعأ. انتشارات سنا. تهران. ايران.

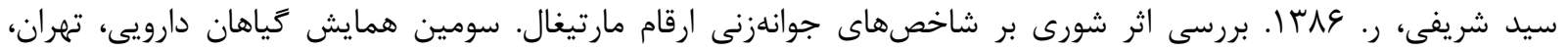
دانشخاه شاهد. آبان ماه. صفحه V.r.

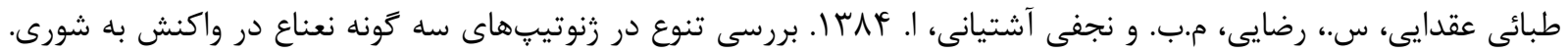

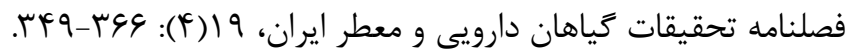

فرخى، آ. و گالشى، س. ع إl. بررسى تأثير شورى، اندازه بذر و اثرات برهمكنش آنها بر تندش، كارايى تبديل ذخاير بذر و

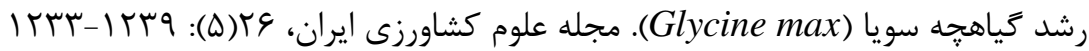

مقبلى، ط. و آروين، م. ج. سوجا. اثر آماده سازى بذر با تنظيم كنندههاى رشد بر خصوصيات جوانهزنى، رشد و عملكرد ميوه

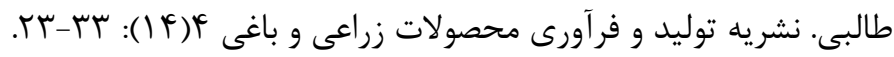

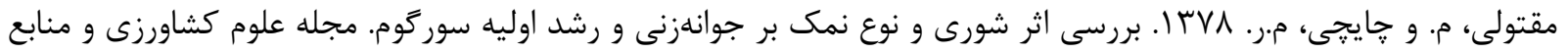

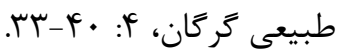
ملائى، ز. و تقوايى، م. بوجا ا. تاثير شورى بر بنيه اوليه استبرق (Calotropis procera L.). سيزدهمين همايش علوم زراعت و اصلاح نباتات ايران و سومين همايش علوم و تكنولوزى بذر ايران، انجمن علوم زراعت و اصلاح نباتات ايران إنبئ

Calendula ( موسوى، ر. •وبا. اثرات اسيد جاسمونيك و ساليسيليك اسيد بر خاصيت فيتوشيميايى گل هميشهبهار officinalis L.

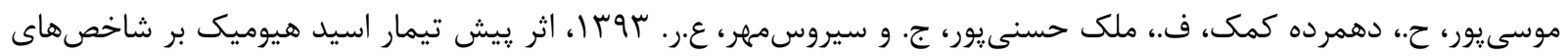

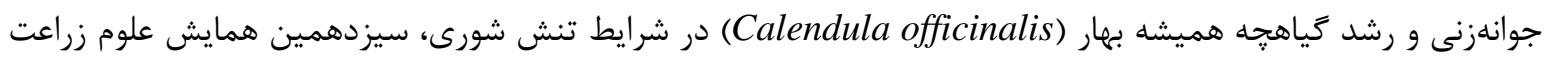

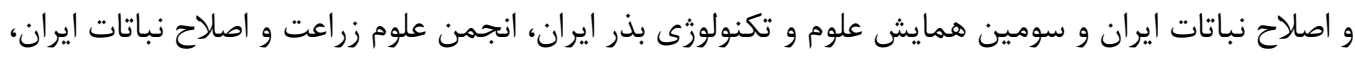

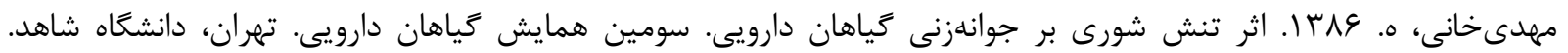
صفحd If

Abdul-Baki, A.A., and Anderson, J.D. 1973. Vigor determination in Soybean by multiple criteria.

Crop Science, 10: 31-34. https://doi.org/10.2135/cropsci1970.0011183X001000010012x 
Akbari, G., Modarres Sanavy, S.A.M., and Yousefzadeh, S. 2007. Effect of auxin and salt stress $(\mathrm{NaCl})$ on seed germination of wheat cultivars (Triticum aestivum L.). Pakistan Journal of Biological Sciences, 10(15): 2557-2561. https://doi.org/10.3923/pjbs.2007.2557.2561

Asgharipour, M.R., and Rafiei, M. 2011. The Effect of different concentrations of humic acid on seed germination behavior and vigor of barley. Australian Journal of Basic and Applied Sciences, 5(12): 610-613.

Avanci, N.C., Luche, D.D., Goldman G.H., and Goldman M.H.S. 2010. Jasmonates are phytohormones with multiple functions, including plant defense and reproduction. Genetics and Molecular Research, 9(1): 484- 505. https://doi.org/10.4238/vol9-1gmr754

Aziz, E., Gad, N., and Badran, N.M. 2007. Effect of cobalt and nickel on plant growth, yield and flavonoids content of Hibiscus sabdariffa (L.). Australian Journal of Basic Applied Sciences, 1(2): 73-78.

Burnett, S. E., Pennisi, S.V., Thomas, P.A., and van Iersel, M.W. 2005. Controlled drought affects morphology and anatomy of Salvia splendens. Journal of the American Society for Horticultural Science, 130(5): 775-781.

Chauhan, B.S., Gill G., and Preston C. 2006. Factors affecting seed germination of annual sow thistle (Sonchus oleraceus) in southern Australia. Weed Science, 54(5): 854-860. https://doi.org/10.1614/WS-06-047R.1

Cheong, J. J., and Choi, Y. 2003. Methyl jasmonate is a vital substance in plants. Trends in Genetics, 19(7): 409-413. https://doi.org/10.1016/S0168-9525(03)00138-0

Chewonarin, T., Kinouchi, T., Kataoka, K., Arimachi, H., Kuwahara, T., Initkekumnuen, U., and Ohnishi, Y. 1999. Effects of roselle (Hibiscus sabdariffa Linn.), a Thai medicinal plant, on the mutagenicity of various known mutagens in Salmonella typhimurium and on formation of aberrant crypt foci induced by the colon carcinogens azoxy methane and 2-amino-methyl-6 phenylimidazo (4, 5-b) pyridine in F344 rats. Food and Chemical Toxicology, 37(1): 591-601. https://doi.org/10.1016/S0278-6915(99)00041-1

Coolbear, P., Francis, A., and Grierson, D. 1984. The effect of low temperature pre-sowing treatment on the germination performance and membrane integrity of artificially aged tomato seeds. Journal of Experimental Botany, 35(11): 1609-1617. https://doi.org/10.1093/jxb/35.11.1609

Creelman, R., and Mullet, G.E. 1997. Biosynthesis and action of Jasmonate in plant. Annual Review of Plant Physiology and Plant Molecular Biology, 48(1): 355-381.

https://doi.org/10.1146/annurev.arplant.48.1.355

Duke, J.A. 1983. Malvaceae roselle. In: Handbook of energy crops, 345-369.

Emongor, V.E., Chweya, J.A., Keya, S.O., and Munavu, R.M. 1990. Effect of nitrogen and phosphorus on the essential oil yield and quality of chamomile (Matricaria chamomilla L.) flowers. East African Agricultural and Forestry Journal, 55(4): 261-264.

Enteshari, Sh., and Jafari, T. 2013. The effects of methyl jasmonate and salinity on germination and seedling growth in Ocimum basilicum L. Iranian Journal of Plant Physiology, 3: 749-756.

Faraji, M., and Tarkhani, A. 1999. The effect of sour tea (Hibiscus sabdariffa) on essential hypertension. Journal of Ethnopharmacology, 65: 231-236. https://doi.org/10.1016/S0378-8741(98)00157-3 
Gao, X.P., Wang, X.F., Lu, Y.F., Hang, L.Y., Shen, Y.Y., Liang, Z., and Zhang, D.P. 2004. Jasmonic acid is involved in the water-stress induced betaine accumulation in pear leaves. Plant Cell and Environment, 27(4): 497-507. https://doi.org/10.1111/j.1365-3040.2004.01167.x

Godfery, W.N., Onyango J.C., and Beck. E. 2007. Sorghum and salinity: 2. Gas exchange and chlorophyll fluorescence of sorghum under salt stress. Crop Science, 44: 806-811.

Guvence, I., Dursun, A., Turan, M., Tuzel. Y., Burrage, S.W., Bailey, B.J., Gul, A., Smith A.R., and Tuncay, O. 1999. Effect of different foliar fertilizers on growth, yield and nutrient content of lettuce and crisp lettuce. Acta Horticulturae, 491: 247-252. https://doi.org/10.17660/ActaHortic.1999.491.36

Jack, H., and Evans, M. 2000. Humic acid seed and substrate treatments promote seedling root development. Horticulture Science, 35(7):1231-1233.

Jami Al-Ahmadi, M., and Kafi, M. 2006. Salinity effects on germination properties of Kochia scoparia. Asian Journal of Plant Sciences, 5(1): 71-75. https://doi.org/10.3923/ajps.2006.71.75

Jamil, M., Lee, D.B., Jung, K.Y., Ashraf, M., Lee, S.C., and Rha, E.S. 2006. Effect of salt (NaCl) stress on germination and early seedling growth of four vegetables species. Journal of Central European Agriculture, 7(2), 273-282.

Kline, S.W., and Wilson Jr, C.E. 1994. Proposal for experimentation with Arkansas lignite to identify organic soil supplements suitable to regional agricultural needs. Preliminary draft. Arkansas Tech University.

Korkmaz, A., Ozbay, N., Tiryaki, I. and Nas, M. N. 2005. Combining priming and plant growth regulators improves muskmelon germination and emergence at low temperatures. European Journal of Horticultural Science, 70(1): 29-34.

Korkmaz, A., Tiryaki I., and Nas, M.N. 2005. Combining priming and plant growth regulators improves muskmelon germination and emergence at low temperatures. European Journal of Horticultural Science, 70(1): 29-34.

Korkmaz, A., Tiryaki, I., Nas, M.N., and Ozbay, N. 2004. Inclusion of plant growth regulators into priming solution improves low-temperature germination and emergence of watermelon seeds. Journal of Plant Science, 1161-1167.

Larcher, W. 2001. Physiological plant ecology. Springer-Verlag Berlin Heidelberg New York Germany, 505.

Maghsoudi Moud, A., and Maghsoudi, K. 2008. Salt stress effects on respiration and growth of germinated seeds of different wheat (Triticum aestivum L.) cultivars. World Journal of Agricultural Sciences, 4(3): 351-358.

Maksymiec, W. 2011. Effects of jasmonate and some other signaling factors on bean and onion growth during the initial phase of cadmium action. Biologia Plantarum, 55(1): 112-118.

https://doi.org/10.1007/s1053 5-011-0015-9

Malik, K.A., and Azam, F. 1985. Effect of humic acid on wheat (Triticum aestivum L.) seedling growth. Environmental and Experimental Botany, 25(3): 245-252.

https://doi.org/10.1016/0098-8472(85)90008-5

Nardi, S., Pizzeghello, D., Muscolo, A., and Vianello, A. 2002. Physiological effects of humic substances on higher plants. Soil Biology and Biochemistry, 34(11): 1527-1536.

https://doi.org/10.1016/S0038-0717(02)00174-8 
Piccolo, R.F., Judge, T.A., Takahashi, K., Watanabe, N., and Locke, E.A. 2005. Core self-evaluations in Japan: relative effects on job satisfaction, life satisfaction, and happiness. Journal of Organizational Behavior, 26: 965-984. https://doi.org/10.1002/job.358

Prasad, M.R.N. 1997. Plant ecophysiology. John Wiley \& Sons. New York, 542 p.

Radosevich, S.R., Holt, J.S., and Ghersa, C. 1997. Weed ecology: implications for management. John Wiley \& Sons. New York.

Rauf, M., Munir, M, Hassan, M.U., Ahmad M., and Afzal, M. 2007. Performance of wheat genotypes under osmotic stress at germination and early seedling growth stage. African Journal of Biotechnology, 6: 971-975.

Rezaei, S., Orojloo, M., Bidabadi, S.S., and Soleimanzadeh, M. 2013. Possible role of Methyl Jasmonate in protection to $\mathrm{NaCl}-$ induced salt stress in pepper CV. Sabz Hashemi. International Journal of Agriculture and Crop Sciences, 6(17): 1235-1238.

Sairam, R.K., Srivasta, G.C., Agarwal, S., and Meena, R.C. 2005. Difference in antioxidant activity in response to salinity stress in tolerant and susceptible wheat genotypes. Biologial Planetarium, 49(1): 85-91. https://doi.org/10.1007/s10535-005-5091-2

Senaratna T., Touchell, D., Bun, E., and Dixon, K. 2000. Acetyl salicylic acid (Aspirin) and salicylic acid induce multiple stress tolerance in bean and tomato plant. Plant Growth Regulation, 30(2): 157-161. https://doi.org/10.1023/A:1006386800974

Shirasu, K., Nakajima, A., Rajshekar, K., Dixon, R.A., and Lamb, C. 1997. Salicylic acid potentiates an agonist-dependent gain control that amplifies pathogen signal in the activation of defense mechanism. The Plant Cell, 9: 261-270. https://doi.org/10.2307/3870546

Soltani, A., Galeshi, S. Zainali, E., and Latifi, N. 2001. Germination, seed reserve utilization and seedling growth of chickpea as affected by salinity and seed size. Seed Science Technology, 30: 5160 .

Stoynova-Bakalova, E., Nikolova, M., and Maksymiec, W. 2009. Effects of Cu2+, cytokinins and jasmonate on content of two flavonols identified in Zucchini cotyledons. Acta Biological Cracoviensia Series Botanica, 51(2): 77-83.

Tattini, M., Bertoni, P., Landi, A., and Traversi, M.L. 1991. Effect of humic acids on growth and biomass partition of container grown olive plant. Acta Horticulturae, 294: 75-80.

https://doi.org/10.17660/ActaHortic.1991.294.7

Van de Venter, A. 2001. Seed vigor testing. Journal of New Seeds, 2(4): 51-58. https://doi.org/10.1300/J153v02n04_06

Young, C.C., and Chen, L.F. 1997. Polyamines in humic acid and their effect on radical growth of lettuce seedlings. Plant and Soil, 195: 143-149. https://doi.org/10.1023/A:1004247302388 


\title{
A Study into the Effect of Jasmonic and Humic Acids on Some Germination Characteristics of Rosselle (Hibiscus sabdariffa) Seed under Salinity Stress
}

\author{
Hamide Azad ${ }^{1}$, Bahman Fazeli-nasab ${ }^{2, *}$, Ali Sobhanizadeh ${ }^{3}$ \\ ${ }^{I}$ M.Sc. of Horticulture Plant Breeding, Graduated from University of Zabol, Zabol, Iran. \\ ${ }^{2}$ Faculty Scientific Member, Research Dept.of Agronomy and Plant Breeding, Agricultural \\ Research Institute, University of Zabol, Zabol, Iran \\ ${ }^{3}$ M.Sc. of Horticultural Plant Breeding, Graduated from University of Zabol, Zabol, Iran \\ "Corresponding author, E-mail address: Bfazeli@uoz.ac.ir
}

(Received: 11.06.2016; Accepted: 12.04.2017)

\begin{abstract}
An experiment was conducted to investigate the effects of jasmonic and humic acids on some seed germination characteristics of Roselle under the salt stress condition in a factorial experiment, adopting a completely randomized design with three replications. Treatments included four different levels of salinity stresses: 0, 70, 140 and $210 \mathrm{mM}$; four levels of Jasmonic Acid: 0, 50, 150 and $200 \mathrm{mM}$ and three levels of humic acid: 0,40 and $80 \mathrm{mM}$. The results showed that the effect of salinity on all the traits studied was significant except the ratio of the length of root and shoot. With an increase in salinity stress condition from 70 to $210 \mathrm{mM}$, there were $39 \%$ decrease in germination percentage, $55 \%$ in germination rate, $45 \%$ in fresh and dry weight, $30 \%$ in root length, $42 \%$ in shoot length, $37 \%$ in seedling length, $67 \%$ in longitudinal index and $61 \%$ in the weighted power, as compared with the control. However, the longitudinal power index increased. In addition, the use of jasmonic acid and humic acids had a significant effect on the traits studied. The interaction of the salt and hormones had a significant impact on plant fresh and dry weight, the length of the root, germination percentage, power weight index and average time needed for 50 percent germination. Given that the highest rate of root length and plant fresh and dry weight belonged to the interaction of humic and jasmonic acid in the absence of salinity, that in the presence of humic acid (with $80 \mathrm{mM}$ concentration), Rosselle can bear salinity up to $140 \mathrm{mM}$ and maintain stamina root length and that the germination rate of Rosselle increases by adding jasmonic acid up to $200 \mathrm{mM}$, one can conclude that the interaction of jasmonic and humic acids not only improves germination rate, but it also contributes to root length because, with an increase in root length, Rosselle can bear water stress conditions.
\end{abstract}

Keywords: Hibiscus sabdariffa, Humic acid, Jasmonic acid, NaCl, Seed vigor index

\section{Highlights:}

1- Jasmonic acid and humic acid increase the Rosselle germination in salinity condition.

2- Jasmonic acid and humic acid increase Rosselle the root length in salinity condition. 